Article

\title{
Synthetic and Structural Study of peri-Substituted Phosphine-Arsines
}

\author{
Brian A. Chalmers ${ }^{1}{ }^{1}$, D. M. Upulani K. Somisara ${ }^{1}$, Brian A. Surgenor ${ }^{2}$, Kasun S. Athukorala Arachchige ${ }^{3}$, \\ J. Derek Woollins ${ }^{1,4}{ }^{(\mathbb{D}}$, Michael Bühl ${ }^{1}$, Alexandra M. Z. Slawin ${ }^{1}$ (D) and Petr Kilian ${ }^{1, *(D)}$ \\ 1 EaStChem School of Chemistry, University of St Andrews, St Andrews KY16 9ST, UK; \\ bac8@st-andrews.ac.uk (B.A.C.); dmuks@st-andrews.ac.uk (D.M.U.K.S.); jdw3@st-andrews.ac.uk (J.D.W.); \\ mb105@st-andrews.ac.uk (M.B.); amzs@st-andrews.ac.uk (A.M.Z.S.) \\ 2 Treatt Plc, Bury St Edmunds IP32 7FR, UK; brian.surgenor@treatt.com \\ 3 Centre for Microscopy and Microanalysis, The University of Queensland, St Lucia, QLD 4072, Australia; \\ kasun.athukorala@uq.edu.au \\ 4 Department of Chemistry, Khalifa University, Abu Dhabi 127788, United Arab Emirates \\ * Correspondence: pk7@st-andrews.ac.uk
}

Citation: Chalmers, B.A.; Somisara, D.M.U.K.; Surgenor, B.A.; Athukorala Arachchige, K.S.; Woollins, J.D.; Bühl, M.; Slawin, A.M.Z.; Kilian, P. Synthetic and Structural Study of peri-Substituted Phosphine-Arsines. Molecules 2021, 26, 7222. https:// doi.org/10.3390/molecules26237222

Academic Editor: Andrzej Grzechnik

Received: 29 October 2021

Accepted: 23 November 2021

Published: 28 November 2021

Publisher's Note: MDPI stays neutral with regard to jurisdictional claims in published maps and institutional affiliations.

Copyright: (c) 2021 by the authors. Licensee MDPI, Basel, Switzerland. This article is an open access article distributed under the terms and conditions of the Creative Commons Attribution (CC BY) license (https:// creativecommons.org/licenses/by/ $4.0 /)$.

\begin{abstract}
A series of phosphorus-arsenic peri-substituted acenaphthene species have been isolated and fully characterised, including single crystal X-ray diffraction. Reactions of $\mathrm{EBr}_{3}(\mathrm{E}=\mathrm{P}, \mathrm{As})$ with $i \operatorname{Pr}_{2}$ PAcenapLi (Acenap = acenaphthene-5,6-diyl) afforded the thermally stable peri-substitution supported donor-acceptor complexes, $i \operatorname{Pr}_{2} \mathrm{PAcenapEBr}_{2} \mathbf{3}$ and 4 . Both complexes show a strong $\mathrm{P} \rightarrow \mathrm{E}$ dative interaction, as observed by $\mathrm{X}$-ray crystallography and ${ }^{31} \mathrm{P}$ NMR spectroscopy. DFT calculations indicated the unusual As $\cdots$ As contact $(3.50 \AA)$ observed in the solid state structure of 4 results from dispersion forces rather than metallic interactions. Incorporation of the excess $\mathrm{AsBr}_{3}$ in the crystal structure of 3 promotes the formation of the ion separated species $\left[i \mathrm{Pr}_{2} \mathrm{PAcenapAsBr}\right]^{+} \mathrm{Br}^{-} \mathbf{5}$. A decomposition product 6 containing the rare $\left[\mathrm{As}_{6} \mathrm{Br}_{8}\right]^{2-}$ heterocubane dianion was isolated and characterised crystallographically. The reaction between $i \mathrm{Pr}_{2} \mathrm{PAcenapLi}$ and EtAsI $\mathrm{I}_{2}$ afforded tertiary arsine (BrAcenap) ${ }_{2} \mathrm{AsEt} 7$, which was subsequently lithiated and reacted with $\mathrm{PhPCl}_{2}$ and $\mathrm{Ph}_{2} \mathrm{PCl}$ to afford cyclic $\mathrm{PhP}(\text { Acenap })_{2}$ AsEt 8 and acyclic EtAs $\left(\text { AcenapPPh }_{2}\right)_{2} 9$.
\end{abstract}

Keywords: peri-substitution; arsenic; organophosphorus; pnictine; single crystal X-ray structures

\section{Dedication}

This paper is dedicated to Prof Alex Slawin on the occasion of her 60th birthday, a world class crystallographer, a caring and compassionate colleague and mentor.

\section{Introduction}

Phosphines $\left(\mathrm{R}_{3} \mathrm{P}\right)$ are known as prototypical neutral donors (Lewis bases) with the most common examples being their use as tunable ligands in coordination chemistry [1,2]. Bonding occurs through donation of the phosphorus lone pair into an acceptor orbital on the metal ( $\sigma$-component), often combined with the acceptance of electron density from the metal orbitals to empty orbitals on the phosphine ( $\pi$-component). Arsines are also used as ligands, although their use is somewhat limited by their greater toxicity.

Although possessing a lone pair of electrons, both phosphines and arsines can also act as electron pair acceptors (Lewis acids) when equipped with electron withdrawing substituents, such as halogens [3].

For this paper, dative species in which a phosphine acts as donor, and another phosphine or arsine acts as acceptor, are of interest. Holmes experimented with various pnictogen compounds to form pnictogen-pnictogen donor-acceptor complexes, and in all cases, decomposition occurred at ambient temperatures [4,5]. For example, the reaction between $\mathrm{Me}_{3} \mathrm{P}$ and $\mathrm{PCl}_{3}$ (both colourless liquids) afforded a white solid of the composition 
$\left(\mathrm{Me}_{3} \mathrm{P}\right)_{2} \cdot \mathrm{PCl}_{3}$ at temperatures below freezing, the solid however decomposed upon warming [5]. Sisler then investigated the decomposition pathways and discovered redox degradation occurred readily at ambient conditions (e.g., $\mathrm{Et}_{3} \mathrm{P}+\mathrm{MePCl}_{2} \rightarrow \mathrm{Et}_{3} \mathrm{PCl}_{2}+(\mathrm{MeP})_{5}$ ) [6].

It was not until 2001 that the first examples of phosphine-phosphine donor-acceptor species, $\mathrm{Me}_{3} \mathrm{P} \rightarrow \mathrm{PBr}_{3}$ and $\mathrm{Me}_{3} \mathrm{P} \rightarrow \mathrm{Bz}^{\prime} \mathrm{PBr}_{2}\left(\mathrm{Bz}^{\prime}=3,5\right.$-dimethylbenzyl), were structurally characterised by Müller and Winkler (Figure 1) [7]. Even so, these two adducts still decomposed at ambient conditions.<smiles>Cc1cc(C)cc(C[P+](Br)(Br)P(C)(C)(C)C)c1</smiles>

Figure 1. The first structurally characterised phosphine-phosphine donor-acceptor complexes.

The first room temperature stable phosphine-phosphine donor-acceptor complex, ( $i \mathrm{Pr}_{2} \mathrm{PAcenapPCl} \mathrm{P}_{2}($ Acenap $=$ acenaphthene-5,6-diyl), was isolated almost a decade later by us [8]. With peri-substitution enforcing the interaction between the two phosphorus atoms, the resulting strong dative interaction and reduced flexibility makes the redox decomposition pathways less accessible, allowing isolation and manipulation of these dative species at ambient temperatures.

Donor-acceptor species with heavier acceptor pnictogens were reported to be more stable owing to their reduced propensity to the redox decomposition pathways. Thus, while $\mathrm{Me}_{3} \mathrm{P} \rightarrow \mathrm{PCl}_{3}$ decomposes above $-20{ }^{\circ} \mathrm{C}$, [9] $\left(\mathrm{Me}_{3} \mathrm{P}\right)_{2} \rightarrow \mathrm{SbCl}_{3}$ and $\mathrm{Me}_{3} \mathrm{As} \rightarrow \mathrm{SbCl}_{3}$ are stable at ambient conditions and melt with decomposition at $110^{\circ} \mathrm{C}[10]$ and $145^{\circ} \mathrm{C}[4,11]$, respectively. In his early study, Sisler reported on the prototypical $\mathrm{R}_{3} \mathrm{Pn}^{\prime} \rightarrow \mathrm{PnX}_{3}$ pnictogenpnictogen donor-acceptor complexes. Their stability was increased for heavier halogens in the acceptor species $(\mathrm{I}>\mathrm{Br}>\mathrm{Cl}>\mathrm{F}$ ) and followed the trend $\mathrm{Sb}>\mathrm{As}>\mathrm{P}$ for the $\mathrm{Pn}$ in the acceptor species $\left(\mathrm{PnX}_{3}\right)$, while the stability trend $\mathrm{As}>\mathrm{P}>\mathrm{Sb}$ was observed for $\mathrm{Pn}^{\prime}$ in the donor species $\left(\mathrm{R}_{3} \mathrm{Pn}^{\prime}\right)$ [9]. The stability of these and related dative species is likely to be driven by the difference in the Lewis acidity and basicity of the donor and acceptor (i.e., the strength of the dative bond), combined with the redox properties of the two components (i.e., the reducing and oxidising power of these). Comprehensive accounts on neutral [12] and related cationic species $[13,14]$ have been published recently, encompassing the variety of the structural modes adopted by main group pnictine complexes.

In the last two decades, we and others focused our attention on the peri-substituted pnictogen-pnictogen donor-acceptor complexes as shown in Figure 2.

Among complexes with dihalopnictines as acceptors, four structural types have been observed, including two molecular modes (A, B), $\mu$-dichloro-bridged dimer $\mathbf{C}$ and fully ionic species D. Monohalopnictogen adducts attain two structural types, D (ionic) and B (molecular). 

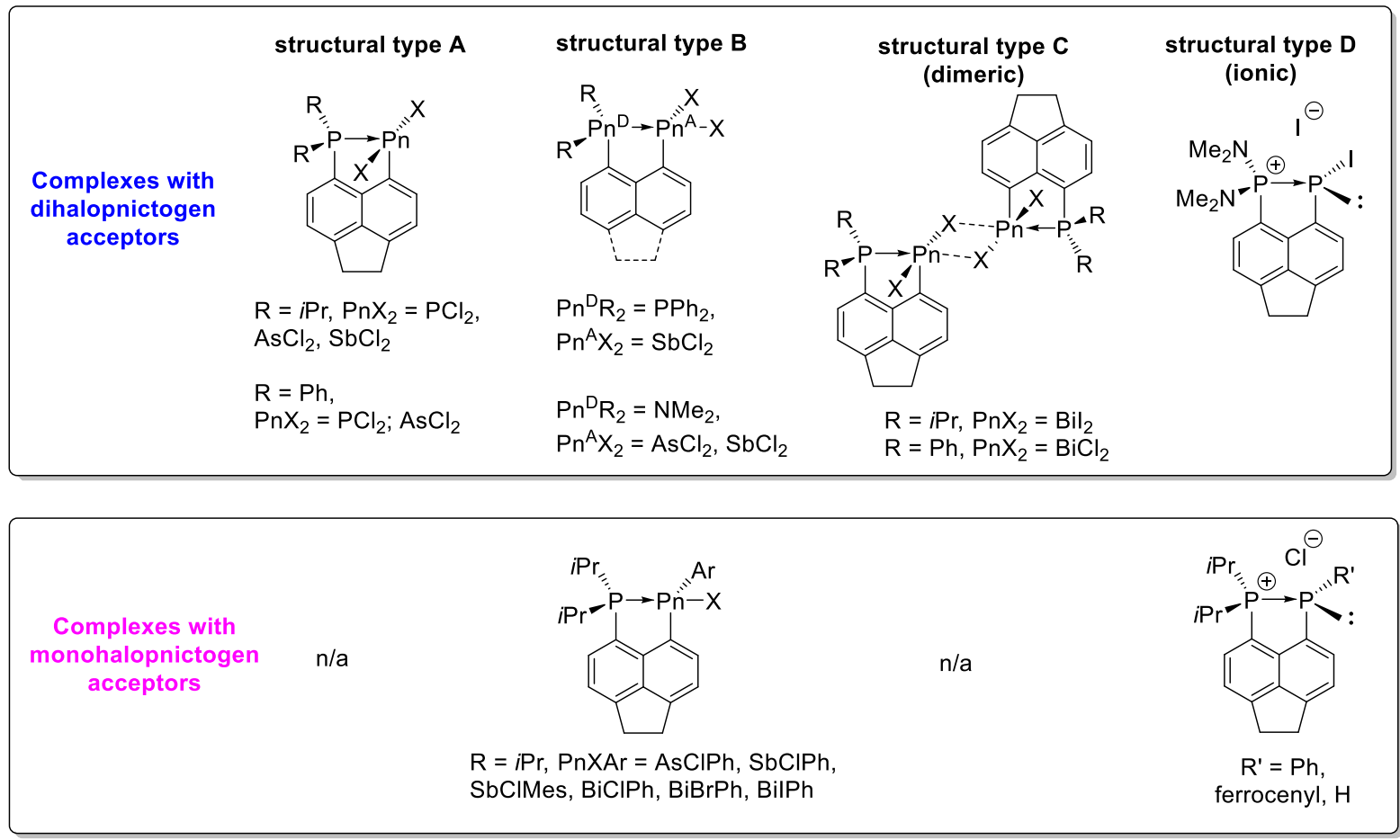

Figure 2. Selected structurally characterised peri-substituted pnictine-pnictine donor-acceptor complexes, indicating their structural diversity $[8,15-23]$.

Motivated by the utility of dihalopnictines as precursor molecules in the development of new radical $\mathrm{C}-\mathrm{H}$ coupling reactions [21], our attention turned to related species with dibromopnictine acceptor groups. Replacement of chlorine atoms with bromine was expected to alter thermal stability (through altering redox properties) and solubility in organic solvents (through altering the aggregation properties); both thermal stability and solubility are important for the synthetic utility of these dihalides. We also report on the chemistry of a geminal bis(acenaphthene)arsine, specifically its ability to tolerate treatment with $n \mathrm{BuLi}$ without cleavage of the As-C bonds. This opens up new synthetic pathways to further $\mathrm{P}$ and As peri-substituted species, some of which may serve as the $\mathrm{C}-\mathrm{H}$ coupling precursors as mentioned above.

\section{Results \& Discussion}

\subsection{Reactions Involving $\mathrm{PBr}_{3}$ and $\mathrm{AsBr}_{3}$}

In the syntheses described herein, 5,6-dibromoacenaphthene, 1, was used as the principal precursor. Two subsequent lithium-halogen exchanges, followed by reactions with pnictogen halide electrophiles, were used to access the variety of peri-substitution patterns shown in Scheme 1.

5-Bromo-6-(diisopropylphosphino)acenaphthene 2 was prepared using our literature procedure [8]. Lithiation of 2 using $n \mathrm{BuLi}$, followed by a slow addition of the formed $i \mathrm{Pr}_{2} \mathrm{PAcenapLi}$ to a fivefold excess $\mathrm{PBr}_{3}$, gave the phosphonium-phosphoranide $3\left(\mathrm{iPr}_{2} \mathrm{PAcenapPBr}_{2}\right)$ in a good yield $(65 \%)$. The related phosphonium-arsoranide $4\left(\mathrm{Pr}_{2} \mathrm{PAcenapAsBr}_{2}\right)$ was made using the same procedure in $~ 75 \%$ yield; however, in this case, only one molar equivalent of $\mathrm{AsBr}_{3}$ was used in the reaction. The selectivity of the reactions of aryllithiums towards pnictogen halides $\mathrm{PnX}_{3}(\mathrm{Pn}=$ pnictogen) is affected greatly by the order and rate of the reactant addition and the stoichiometric ratio of the reagents. A large excess of the pnictogen halide is often necessary in order to promote monosubstitution giving $\mathrm{R}_{2} \mathrm{PAcenapPnX}_{2}$, i.e., to avoid geminal di- or trisubstitution, leading to the formation of $\left(\mathrm{R}_{2} \mathrm{PAcenap}\right)_{2} \mathrm{PnX}$ or $\left(\mathrm{R}_{2} \text { PAcenap }\right)_{3} \mathrm{Pn}[8,15,17,22,24,25]$. In the preparation of $\mathbf{3}$, the excess $\mathrm{PBr}_{3}$ was necessary to achieve good yields; the excess $\mathrm{PBr}_{3}$ was removed by careful washing with THF and diethyl ether. 


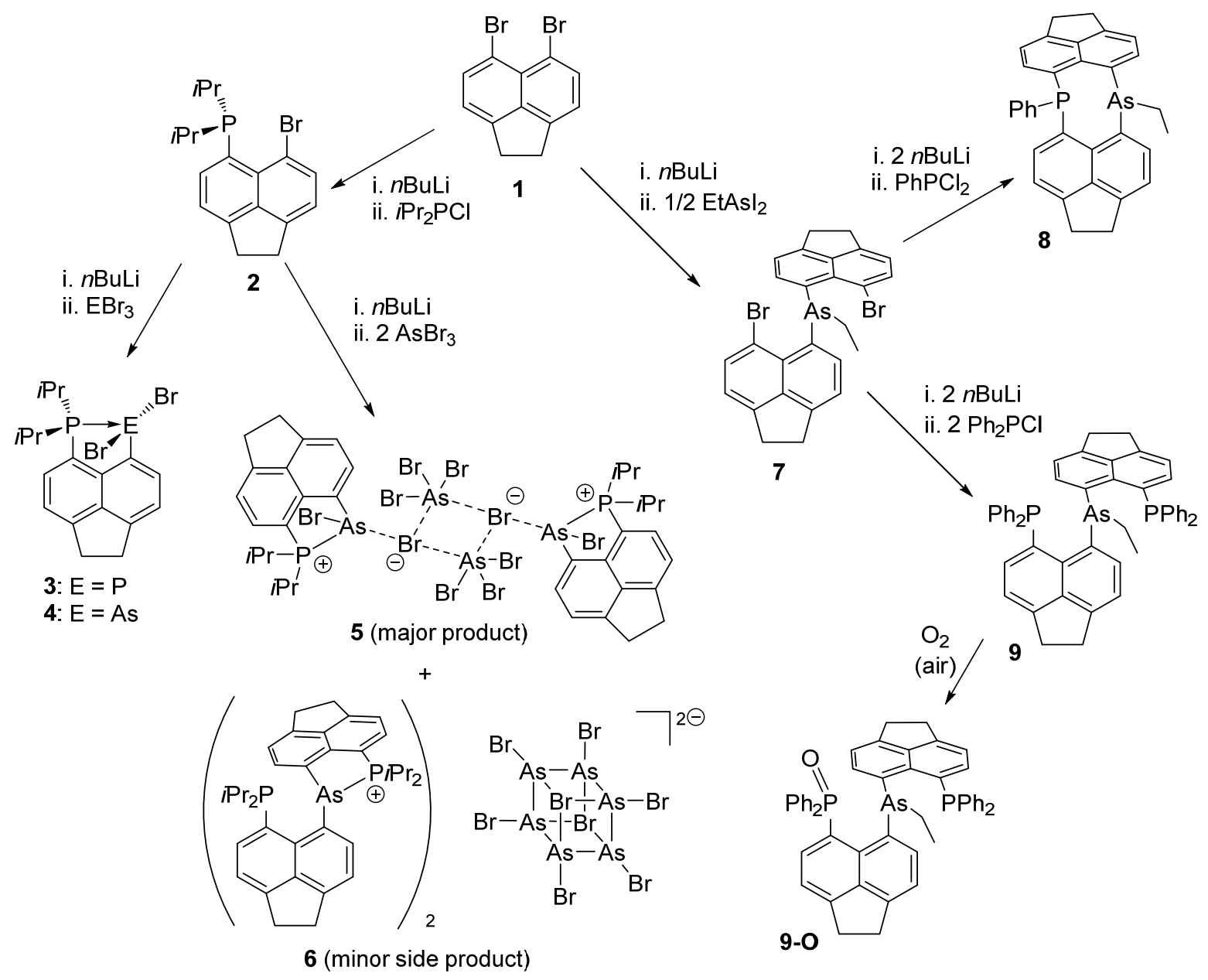

Scheme 1. Syntheses reported in this paper.

Compounds 3 and 4 represent an expansion of the small number of phosphinephosphine and phosphine-arsine donor-acceptor complexes, that are stable (isolable) at ambient temperatures. The unsupported phosphine-phosphine complexes undergo redox degradation at temperatures above $-40{ }^{\circ} \mathrm{C}$ or at even lower temperatures [7]. Both 3 and 4 can be stored indefinitely under inert atmosphere at ambient temperature in the solid form, but 3 undergoes decomposition slowly (over the course of a week) in common organic solvents (thf, dcm, chloroform). The arsenic congener 4 immediately decomposes in chlorinated solvents, giving a mixture of insoluble products. Both $\mathbf{3}$ and $\mathbf{4}$ are air sensitive. It should be noted that the thermal stability and air sensitivity of 3 and 4 is rather similar to that of the chlorine congeners $i \mathrm{Pr}_{2} \mathrm{PAcenapECl}_{2}(\mathrm{E}=\mathrm{P}, \mathrm{As})[8,15]$.

The ${ }^{31} \mathrm{P}\left\{{ }^{1} \mathrm{H}\right\}$ NMR spectrum of 3 consists of two doublets at $\delta_{\mathrm{P}} 65.3\left(i \operatorname{Pr}_{2} \mathrm{P}\right)$ and $32.9 \mathrm{ppm}\left(\mathrm{PBr}_{2}\right)$ with a large ${ }^{1} J_{\mathrm{PP}}$ magnitude of $353.7 \mathrm{~Hz}$ (AX spin system). This is in good agreement with the relevant data of $i \mathrm{Pr}_{2} \mathrm{PAcenapPCl}_{2}\left(\delta_{\mathrm{P}} 68.8\right.$ and $40.4 \mathrm{ppm},{ }^{1} J_{\mathrm{PP}}$ $363 \mathrm{~Hz}$ ) [8]. The ${ }^{31} \mathrm{P}\left\{{ }^{1} \mathrm{H}\right\}$ NMR spectrum of 4 (singlet at $\delta_{\mathrm{P}} 56.6 \mathrm{ppm}$ ) is in agreement with the previously published data for $i \operatorname{Pr}_{2} \mathrm{PAcenapAsCl}_{2}\left(\delta_{\mathrm{P}} 65.3 \mathrm{ppm}\right)$ [15]. This strongly suggests the structures of $\mathbf{3}$ and $\mathbf{4}$ in the solution are similar to those of their chlorine congeners. Significant deshielding of the donor $\left(\mathrm{Pr}_{2} \mathrm{P}\right)$ phosphine group in $\mathbf{3}$ and $\mathbf{4}$ compared to that in $2\left(\delta_{\mathrm{P}}-2.2 \mathrm{ppm}\right)$ strongly suggests major sequestration of the lone pair electron density takes place by the pnictogen halide $\left(\mathrm{PnX}_{2}\right)$ acceptor group. Compounds $\mathbf{3}$ and $\mathbf{4}$ were fully characterised including ${ }^{1} \mathrm{H},{ }^{13} \mathrm{C}\left\{{ }^{1} \mathrm{H}\right\}$ and ${ }^{31} \mathrm{P}\left\{{ }^{1} \mathrm{H}\right\} \mathrm{NMR}$, IR and MS.

The crystal structures of 3 and 4 are shown in Figure 3 and Table 1. The diffraction data indicate a strong dative interaction is formed between the two phosphorus atoms in 3 , with a P-P bond length of 2.2701(16) $\AA$, which is just within a range of standard P-P single 
bond ( $2.22 \pm 0.05 \AA)$. Two molecules of 4 are present in the asymmetric unit. The P-As distances in these (2.405(3) and 2.407(3) $\AA$ ) are crystallographically identical, consistent with a strong dative bond, and comparable to a standard $\mathrm{P}-\mathrm{As}$ single bond length. Based on the electronegativity considerations, the $\mathrm{ECl}_{2}$ group is expected to be better acceptor than the respective $\mathrm{EBr}_{2}$ group $(\mathrm{E}=\mathrm{P}, \mathrm{As})$. However, no dramatic lengthening of the $\mathrm{P} \rightarrow \mathrm{EBr}_{2}$ vs. the $\mathrm{P} \rightarrow \mathrm{ECl}_{2}$ dative bond is observed; the $\mathrm{P}-\mathrm{As}$ bond length in the chlorine congener $i \mathrm{Pr}_{2} \mathrm{P}$-Acenap- $\mathrm{AsCl}_{2}(2.4029(7) \AA$ ) [15] is crystallographically identical to that in 4, while the $\mathrm{P}-\mathrm{P}$ bond length in $i \mathrm{Pr}_{2} \mathrm{PAcenapPCl}_{2}$ (2.2570(14) $\AA$ ) [8] is only marginally shorter than that in 3.
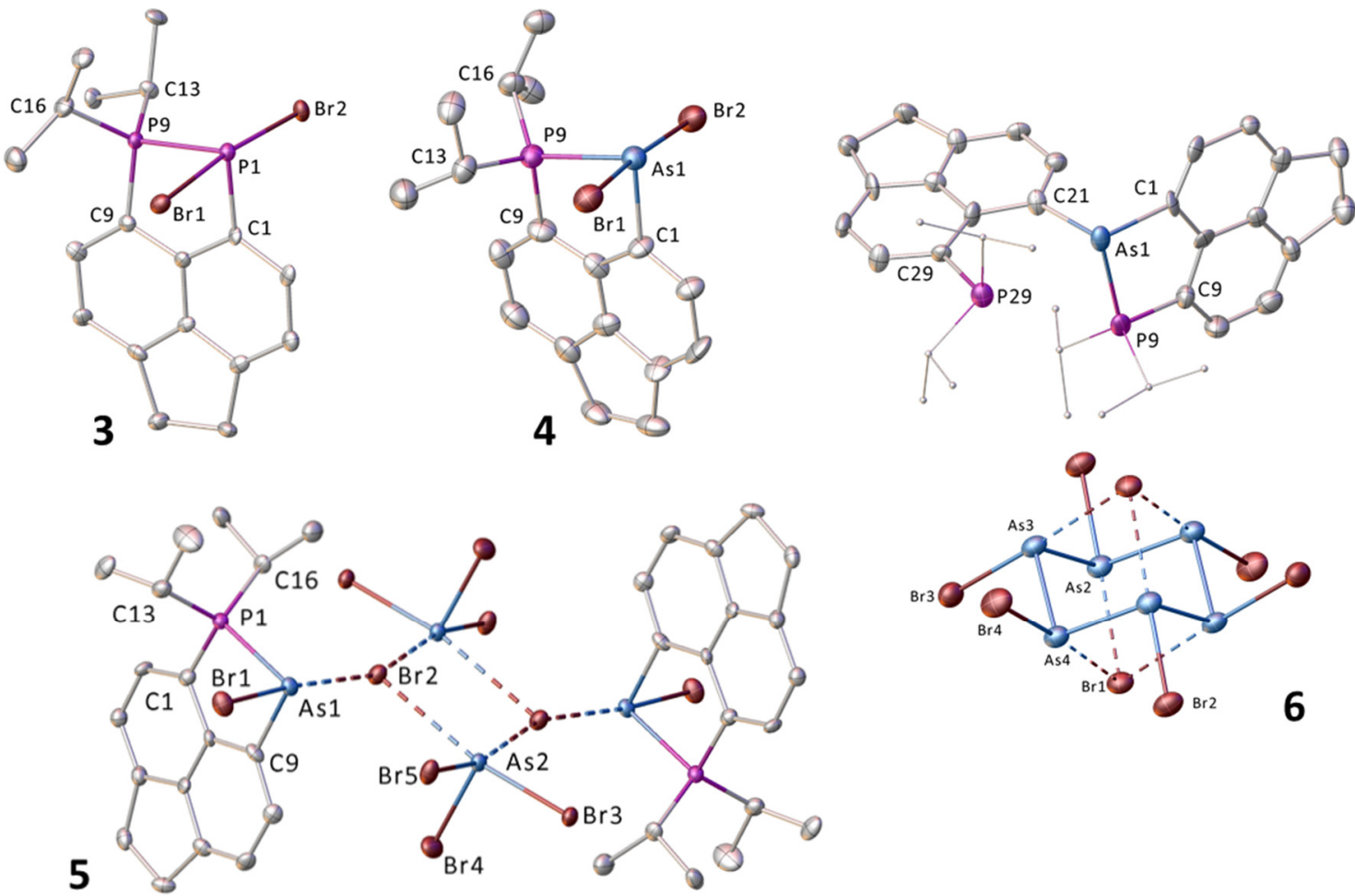

Figure 3. Crystal structures of 3-6. Hydrogen atoms and solvating molecules (THF in 3 and benzene in 4) are omitted. The second molecule in the asymmetric unit of 4 is omitted. 5 forms centrosymmetric dimer, two asymmetric units are shown in the figure. Monocation of 6 is shown at the top, the $\left[\mathrm{As}_{6} \mathrm{Br}_{8}\right]^{2-}$ dianion is at the bottom. Thermal ellipsoid ds are plotted at the $40 \%$ level.

Although neither $\mathbf{3}$ nor $\mathbf{4}$ form a halogen bridged dimeric assemblies in the crystal, the P-Br bond lengths are nonidentical within 3 (P1-Br1 2.6864(13) $\AA$; P1-Br2 2.4376(13) $\AA$ ). In contrast, the As-Br bond lengths are almost identical in 4: As1-Br1 2.6337(19) [2.6339(19)] $\AA$, As1-Br2: 2.6400(18) [2.664(2)] $\AA$ (values in square brackets are for the second molecule in the asymmetric unit). The $\mathrm{P}-\mathrm{Br}$ and $\mathrm{As}-\mathrm{Br}$ bond lengths in $\mathbf{3}$ and $\mathbf{4}$ indicate an intermediate character between ionic and covalent bonds; their elongation is rather significant when compared to the bond lengths in the covalent $\mathrm{PBr}_{5}$ (P-Br: 2.221 and 2.158 $\AA$ ) [26] and $\mathrm{AsBr}_{3}$ (in adduct with hexaethylbenzene, P-As 2.322(1) $\AA$ ) [27]. The acceptor pnictogen atoms in 3 (P1) and 4 (As1) adopt a pseudo-trigonal bipyramidal geometry, with the two bromine atoms occupying the axial positions $\left(\mathrm{Br}-\mathrm{E}-\mathrm{Br} 172.22(5)^{\circ}\right.$ in 3 and $173.95(6)^{\circ}\left[172.27(6)^{\circ}\right]$ in 4). The P9 and $\mathrm{C} 1$ atoms occupy the equatorial positions, with the 3 rd position taken up by the lone pair. The inequality and elongation of the phosphorus-halogen bonds are phenomena observed in all relevant structurally characterised phosphine-phosphine and phosphine-arsine donor-acceptor complexes, and presumably stem mainly from packing effects $[7,8,17]$. The equal length of As-Br bonds, observed within 4, is likely a result of the symmetrical nature of the local polarity effects around the bromine atoms within the crystal structure of 4 . The acenaphthene framework in both 3 and 4 encounters only minimal 
in-plane and out-of-plane distortions from the ideal (planar) geometry, consistent with a relaxed peri-region (P-Pn bonded) structures.

Table 1. Selected bond lengths $\left[\right.$ Ångströms $(\AA)$ ] and angles (degrees, ${ }^{\circ}$ ) for 3 to 9-O.

\begin{tabular}{|c|c|c|c|c|}
\hline Compound & $3 \cdot$ THF $(E=P)$ & $4 \cdot \mathrm{C}_{6} \mathrm{H}_{6}{ }^{[b]}(\mathrm{E}=\mathrm{As})$ & $5(\mathrm{E}=\mathrm{As})$ & $6^{[c]}(E=A s)$ \\
\hline \multicolumn{5}{|c|}{ peri-region bond distances } \\
\hline P9-E1 & $2.2701(16)$ & $2.405(3)[2.407(3)]$ & $2.3978(15)$ & $2.365(4)[3.145(4)]$ \\
\hline E1-Br1 & $2.6864(13)$ & $2.6337(19)[2.6639(19)]$ & $2.4375(9)$ & - \\
\hline E1-Br2 & $2.4376(13)$ & $\begin{array}{l}2.6400(18)[2.634(2)] \\
\text { peri-region angles }\end{array}$ & $3.000(9)$ & - \\
\hline C9-P9-E1 & 97.92(14) & 97.9(3) [98.4(3)] & $97.78(18)$ & $98.7(4)$ \\
\hline C1-E1-P9 & $88.82(13)$ & $84.9(3)[85.3(3)]$ & $86.25(17)$ & $85.7(3)$ \\
\hline Br1-E1-Br2 & $172.22(5)$ & $173.95(6)[172.27(6)]$ & $175.3(2)$ & - \\
\hline P9-E1-Br1 & $91.13(5)$ & $96.01(9)[91.02(9)]$ & $95.57(4)$ & - \\
\hline P9-E1-Br2 & $96.38(5)$ & $90.00(9)[95.95(9)]$ & $88.77(4)$ & - \\
\hline splay angle [a] & $-7.8(5)$ & $-5(1)[-5(1)]$ & $-4(1)$ & $-5(1)[15(1)]$ \\
\hline \multicolumn{5}{|c|}{ out-of-plane displacements } \\
\hline P9 & 0.23 & $0.07[0.10]$ & 0.09 & $0.21[0.12]$ \\
\hline E1 & -0.03 & $-0.36[-0.26]$ & -0.01 & $-0.11[-0.05]$ \\
\hline P9-C9...C1-E & $7.7(2)$ & $10.9(4)[9.2(4)]$ & $2.4(2)$ & $2.8(5)[1.2(5)]$ \\
\hline Compound & $\begin{array}{c}71 / 2 \mathrm{CH}_{2} \mathrm{Cl}_{2} \\
(\mathrm{E}=\mathrm{Br})\end{array}$ & $8 \cdot \mathrm{CH}_{2} \mathrm{Cl}_{2}(\mathrm{E}=\mathrm{P})$ & $9-O(E=P)^{[f]}$ & \\
\hline \multicolumn{5}{|c|}{ peri-region bond distances } \\
\hline As1-E9 & $3.23(1)$ & $3.004(6)$ & $3.176(5)$ & \\
\hline As1-E29 & $3.28(1)$ & - & $3.273(5)$ & \\
\hline \multicolumn{5}{|c|}{ peri-region angles } \\
\hline splay angle $[\mathrm{a}, \mathrm{d}]$ & $17(1)$ & $11.7(4)$ & $16.1(8)$ & \\
\hline splay angle $[\mathrm{a}, \mathrm{e}]$ & 19(1) & $11.4(4)$ & $15.2(8)$ & \\
\hline \multicolumn{5}{|c|}{ out-of-plane displacements } \\
\hline As1 & $0.35,0.02$ & $0.19,0.02$ & $0.04,0.71$ & \\
\hline E9 & -0.08 & -0.03 & -0.40 & \\
\hline E29 & -0.01 & 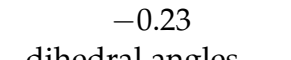 & 0.41 & \\
\hline \multicolumn{5}{|c|}{ dihedral angles } \\
\hline 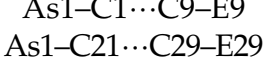 & $\begin{array}{c}12(1) \\
1(1)\end{array}$ & $3.3(6)$ & $\begin{array}{c}8(1) \\
27(1)\end{array}$ & \\
\hline $\mathrm{As} 1-\mathrm{C} 21 \cdots \mathrm{C} 29-\mathrm{E} 29$ & & $5.0(6)$ & $27(1)$ & \\
\hline
\end{tabular}

[a] splay angle $=$ sum of the bay region angles-360. [b] values in square parentheses are for the 2nd molecule in the asymmetric unit. [c] values in square parentheses refer to the P29 acenaphthene unit. [d] C10 acenaphthene unit. [e] C30 acenaphthene unit. [f] E29 in this structure represents P39.

An interesting feature was observed in the crystal packing of 4 . Rather than forming a $\mathrm{Br} \cdots$ As intermolecular close contacts, commonly seen in halogen-bridged dimers $[7,16]$, pairs of molecules of 4 are oriented so that a short (intermolecular) As ...As contact (3.50 $\AA$ ) is formed. To gain some insight into significance of this, we performed density functional theory (DFT) computations on a 'dimer' motif, carved out of the crystal. Because the interaction between the two molecules was expected to be weak, a level was chosen that contains corrections for attractive van der Waals forces (dispersion) and basis-set superposition error (BSSE; an intrinsic error for intermolecular interaction energies with finite basis sets), denoted B3LYP-D3/6-31(+)G* (see SI for details; B3LYP functional and basis sets are the same as in our previous studies on peri-acenaphthene derivatives) $[16,21]$. Interestingly, full geometry optimisation of the dimer at that level affords an even shorter As $\cdots$ As contact $(3.28 \AA)$ than that observed in the solid, and a substantial binding energy $\left(\Delta \mathrm{E}=-15.7 \mathrm{kcal} \mathrm{mol}^{-1}\right.$, estimated $\Delta \mathrm{H}^{298}-14.4 \mathrm{kcal} \mathrm{mol}^{-1}$ and $\Delta \mathrm{G}^{298}-3.43 \mathrm{kcal} \mathrm{mol}^{-1}$ ). Despite this sizeable interaction energy, only small covalent contributions to the binding are apparent from the computed intermolecular Wiberg bond indices (WBIs) [28], which do not exceed 0.05 for both As $\cdots$ As and As $\cdots$ Br contacts. Closer inspection of the contributions to the binding energy $\Delta \mathrm{E}$ reveals that it is entirely dominated by dispersion interactions: the 
-D3 contribution in the optimised structure amounts to $-16.5 \mathrm{kcal} \mathrm{mol}^{-1}$, i.e., the interaction would be expected to be repulsive at the B3LYP level without explicit dispersion correction. Indeed, if the structure is relaxed at the B3LYP/6-31(+) $\mathrm{G}^{*}$ level (still BSSE-corrected), the dimer essentially falls apart. In this scenario, a much longer As $\cdots$ As distance ensues $(3.87 \AA)$ with a very weak binding energy $\Delta \mathrm{E}=-2.1 \mathrm{kcal} \mathrm{mol}^{-1}$, presumably due to weak electrostatic interactions. It is remarkable that the pairs of molecules are held together by such strong dispersion forces, as it brings the arsenic atoms (with their lone pairs pointing toward each other) to an essentially repulsive distance, as shown in Figure 4.

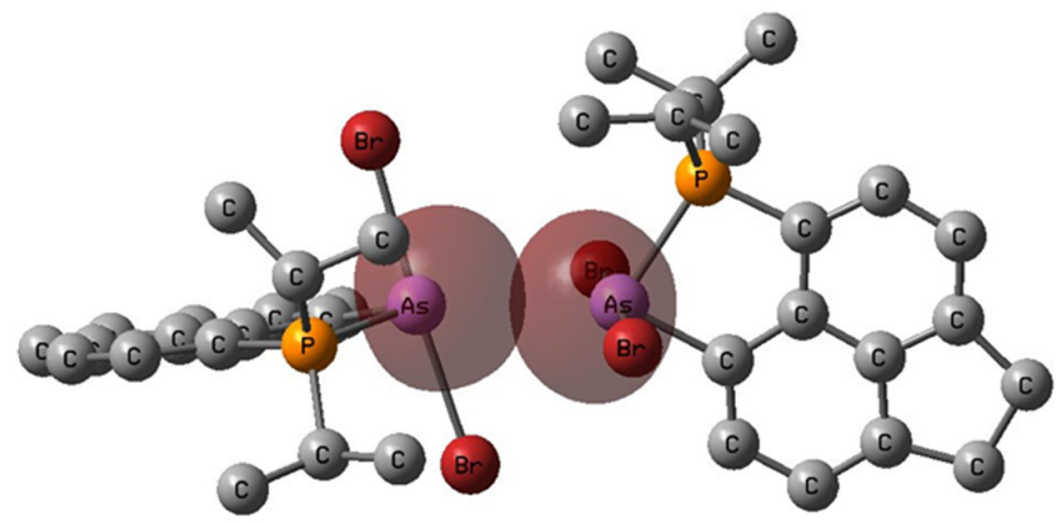

Figure 4. Plot demonstrating overlap of the lone pairs on arsenic atoms in a pair of molecules 4 . Natural bond orbitals, B3LYP/6-31(+)G* level on B3LYP-D3/6-31(+)G* optimised geometry, isovalue for plot 0.04 a.u.; hydrogen atoms omitted for clarity.

Conducting the reaction of $i \mathrm{Pr}_{2}$ PAcenapLi with 2 molar equivalents of $\mathrm{AsBr}_{3}$ gave 5 as a pale-yellow solid, which was contaminated with residual LiBr. Crystals suitable for diffraction work were grown from acetonitrile. The crystal structure of $\mathbf{5}$ is shown in Figure 3 and Table 1 . Compound 5 is formed by an ion pair $\left[i \mathrm{Pr}_{2} \mathrm{PAcenapAsBr}\right]^{+} \mathrm{Br}^{-}$, co-crystallised with an $\mathrm{AsBr}_{3}$ molecule (see Scheme 1), with two acenaphthene units and

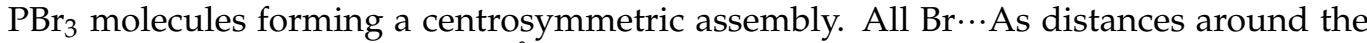
$\mu^{3}$-bridging Br2 atom (3.00-3.04 $\AA$ ) are significantly elongated compared to all other AsBr bonds (2.3370(9)-2.4375(9) ^), supporting the interpretation of the bonding as ionic. Comparing the structures of 4 and 5 shows no significant change in the P-As bond length (2.3978(15) $\AA$ in 5). The most substantial changes are the shortening of the As1-Br1 bond to

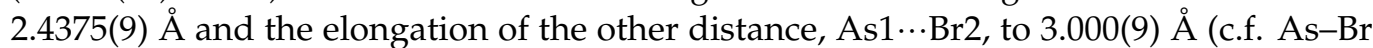
bond lengths 2.634(2)-2.6639(19) $\AA$ in 4).

In one incidence, while attempting to grow crystals of 5 from boiling acetonitrile, a small crop of colourless crystals was obtained. These were subjected to single-crystal X-ray diffraction and were found to be compound 6, consisting of a complex phosphonium cation and an unusual octabromohexaarsenate $\left(\left[\mathrm{As}_{6} \mathrm{Br}_{8}\right]^{2-}\right)$ dianion (Scheme 1, Figure 3 and Table 1). The cation of 6 consists of two acenaphthene groups geminally attached to an arsenic atom. The two $\mathrm{P}-\mathrm{As}$ distances are very disparate, indicating the presence of a standard P9-As1 bond (2.365(4) $\AA$ ), and an onset of 3-center 4-electron P...As-C interaction (P29...As1 3.145(4) $\AA$; P29...As1-C1 angle is $\left.176.9(3)^{\circ}\right)$. A tentative mechanism of the cation formation involves an attack of the second molecule of $i \operatorname{Pr}_{2}$ PAcenapLi on 4 or 5 . Only one previous incidence of crystallographic characterisation of octabromohexaarsenate dianion was found in the literature; this was in the form of its tetraphenylphosphonium salt [29]. The dianion of $\mathbf{6}$ is essentially isostructural to the previously reported example, both can be seen as an $(\mathrm{AsBr})_{6}$ oligoarsine ring in a chair conformation, capped by two bromide anions to form a heterocubane cluster. A tentative mechanism of formation of $\mathbf{6}$ involves thermally induced reduction of $\mathrm{AsBr}_{3}$ (present in the structure of 5), leading to the formation of cyclohexaarsine $(\mathrm{AsBr})_{6}$. This is followed by coordination by bromide anions to give the $\left[\mathrm{As}_{6} \mathrm{Br}_{8}\right]^{2-}$ dianion. The reduction step may be analogous to that seen throughout the chemistry of pnictine-pnictine complexes, first described by Sisler [6], in which the trihalide 
halogenates the tertiary phosphine moiety (to halophosphonium $\left[\mathrm{R}_{3} \mathrm{P}^{\mathrm{V}} \mathrm{Cl}\right]^{+} \mathrm{Cl}^{-}$), reducing itself to $\left(A s^{\mathrm{I} X}\right)_{n}$. This proposed mechanism is distinct (but related) to that proposed by Macdonald for formation of octaiodocyclohexaarsenates, where the diphosphine ligand (L) cleavage from pre-assembled arsenic(I) species [LAs][I] was suggested [30]. Further characterisation of $\mathbf{6}$ was not possible due to the small amount of crystals available. Attempts to repeat synthesis of $\mathbf{6}$ on a larger scale were not successful.

Our attempts to prepare the iodine congener $i \mathrm{Pr}_{2} \mathrm{PAcenapPl}_{2}$ via reaction of $i \mathrm{Pr}_{2} \mathrm{PAcenapLi}$ with $\mathrm{PI}_{3}$ or $\mathrm{P}_{2} \mathrm{I}_{4}$ gave complex mixtures as judged by ${ }^{31} \mathrm{P}$ NMR. On a similar note, reactions of $i \mathrm{Pr}_{2} \mathrm{PAcenapLi}$ with $\mathrm{SbBr}_{3}$ gave inseparable mixtures, presumably via undesirable redistribution and redox processes [9]. This is in stark contrast to the analogous reaction of $i \mathrm{Pr}_{2} \mathrm{PAcenapLi}$ with $\mathrm{SbCl}_{3}$, which afforded the desired donor-acceptor complex $i \mathrm{Pr}_{2} \mathrm{PAcenapSbCl}_{2}$ in an excellent yield [16].

\subsection{Reactions Involving EtAsI}

To expand the range of arsenic peri-substituted species, reactions with ethyldiiodoarsine have been studied. Monolithiation of 5,6-dibromoacenaphthene, followed by an addition of the formed $i \mathrm{Pr}_{2} \mathrm{PAcenapLi}$ to one molar equivalent of EtAsI $\mathrm{I}_{2}$, was expected to yield iodoarsine $\mathrm{Et}(\mathrm{I}) \mathrm{AsAcenapBr}$. However, the ${ }^{1} \mathrm{H}$ NMR spectrum of the white powder obtained after workup indicated a product of a double (geminal) substitution, a tertiary arsine 7, has been formed solely (Scheme 1). The reaction was repeated with highly diluted EtAsI ${ }_{2}$ and very slow addition rate to limit the double substitution, however even then, 7 was the sole product of the reaction.

The crystal structure of $\mathbf{7}$ is shown in Figure 5 and Table 1 . The arsenic atom adopts trigonal pyramidal geometry. The As $\cdots$ Br distances (3.23(1) and 3.28(1) $\AA, 82-83 \%$ of the sum of the respective Van der Waals radii [31]) as well as the large splay angles (17(1) and $\left.19(1)^{\circ}\right)$ indicate repulsive interactions in the peri-region, with As $\cdots \mathrm{Br}$ interactions forced through peri-geometry.

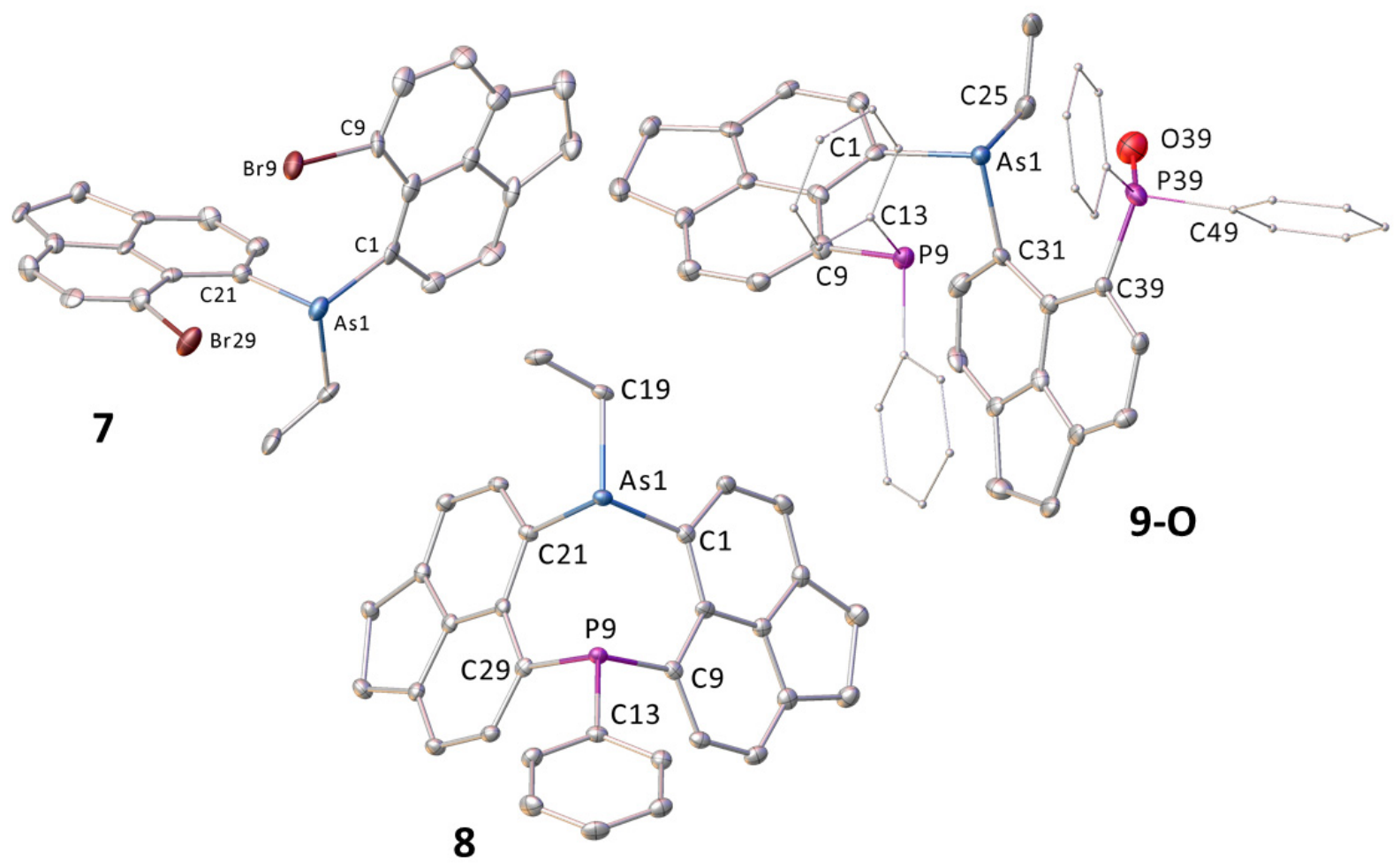

Figure 5. Crystal structures of 7, 8 and 9-O. Hydrogen atoms and solvating molecules $\left(\mathrm{CH}_{2} \mathrm{Cl}_{2}\right.$ in 7 and $\left.\mathbf{8}\right)$ are omitted. Thermal ellipsoids are plotted at the $40 \%$ level. 
Following the clean synthesis of 7 , we were interested in its use as a synthon, particularly its ability to undergo lithium-halogen exchange, which would open many options for its further functionalisation. Initially, we focussed on introducing phosphorus moieties to the peri-positions. Synthesis of two examples, cyclic (8) and acyclic (9), resulted from these efforts (Scheme 1). Using standard low-temperature lithium-halogen exchange conditions, double lithiation of $\mathbf{7}$ was incomplete after several hours at $-78{ }^{\circ} \mathrm{C}$, despite using a slight excess over two equivalents of $n$-butyllithium. To promote the double lithiation we have adopted conditions similar to those reported by Kasai for double lithiation of 5,6-dibromoacenaphthene [32], which included the addition of chelating base tetramethyleethylenediamine, TMEDA. In addition, we have switched to a more polar reaction solvent (thf). These changes sufficiently stabilised the dilithiated species EtAs(AcenapLi) ${ }_{2}$, as the subsequent reaction with $\mathrm{PhPCl}_{2}$ gave cyclic species 8 in a good yield (ca. 70\%). Unfortunately, the workup did not allow for complete removal of the salt impurities as indicated by the results of the elemental analysis, meaning the yield mentioned above is only approximate. 8 showed a sharp singlet at $\delta_{\mathrm{P}}-26.5 \mathrm{ppm}$ and was only barely soluble in common organic solvents, which precluded acquisition of good quality ${ }^{13} \mathrm{C}\left\{{ }^{1} \mathrm{H}\right\}$ NMR spectra.

Reacting the in situ formed dilithiated species EtAs(AcenapLi) $)_{2}$ with two molar equivalents of chlorodiphenylphosphine in thf afforded 9 as the sole phosphorus-containing product as confirmed by ${ }^{31} \mathrm{P}\left\{{ }^{1} \mathrm{H}\right\} \mathrm{NMR}$ spectroscopy (singlet at $\delta_{\mathrm{P}}-19.9 \mathrm{ppm}$ ). 9 was found to be insoluble in many common organic solvents and only sparingly soluble in dichloromethane. In an attempt to grow crystals of $\mathbf{9}$ suitable for $X$-ray work, colourless needle shaped crystals were obtained by diffusion of diethyl ether into a saturated solution of $\mathbf{9}$ in dichloromethane. The X-ray diffraction showed that partial oxidation (presumably by air) has taken place in this sample, giving the phosphine oxide species 9-O. Notably, the presence of the oxidised species 9-O was not evident in the bulk of the reaction product 9 by any other characterisation results such as elemental analysis and mass spectroscopy. Compounds 7-9 were fully characterised, including ${ }^{1} \mathrm{H},{ }^{13} \mathrm{C}\left\{{ }^{1} \mathrm{H}\right\} \mathrm{NMR}$ (where solubility allowed this), IR, Raman and MS.

The crystal structures of $\mathbf{8}$ and $\mathbf{9 - O}$ are shown in Figure 5 and Table 1 . The central part of the molecule of 9 adopts the shape of a puckered (8-membered) ring, with the angle between the two acenaphthene planes being $89^{\circ}$. The molecule of 9-O is rather crowded with large groups attached to the two peri-regions. As mentioned, one of the phosphorus environments in $\mathbf{9 - O}$ is partially oxidised (50\% occupancy) to the phosphine oxide (from accidental exposure to air).

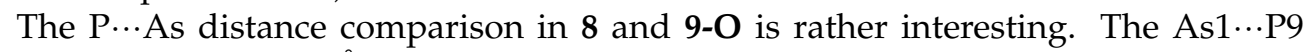
distance in 9-O is 3.176(5) $\AA$, while the relevant distance of 3.004(6) was observed in 8. This indicates the buttressing effect of the double peri-strain in $\mathbf{8}$ is rather significant, shortening the P...As distance by $0.17 \AA$, i.e., by $4.2 \%$ of the sum of the respective Van der Waals radii [31]. The large positive splay angles indicate repulsive interactions in the peri-regions of 7, 8 and 9-O, with the in-plane distortions being the major mechanism of strain relaxation, although in 9-O the arsine group (As1) shows also large out-of-plane displacement $(0.71 \AA$ ) from one of the acenaphthene mean planes.

\section{Experimental}

\subsection{General Considerations}

All reactions and manipulations were carried out under an atmosphere of nitrogen using standard Schlenk techniques or under an argon atmosphere in a Saffron glove box. Dry solvents were either collected from an MBraun Solvent Purification System, or dried and stored according to common procedures [33]. Compounds $\mathbf{1}$ and $\mathbf{2}$ were prepared according to literature procedures [8,34]. Arsenic tribromide was prepared using a modified version of the published procedure (see Supplementary Materials) [35]. EtAsI was prepared as described in the literature [36]. Arsenic oxide (>99.9\%) was purchased from Alfa Aesar and used as received. Other chemicals were purchased from commercial 
sources and used as received. Further experimental details are provided in SI. NMR numbering scheme is shown in Figure 6.<smiles>[R][Z7]([R])c1ccc2c3c(ccc([Z]([R])[R])c13)CC2</smiles>

3: $E^{1} R_{2}=P_{P} P_{2}, E^{2} R_{2}=\mathrm{PBr}_{2}$

4: $E^{1} R_{2}=P_{P P r}, E^{2} R_{2}=A s B r_{2}$

7: $E^{1} R_{2}=$ AsEtAce, $E^{2} R_{2}=B r$

8: $E^{1} R_{2}=$ AsEtAce, $E^{2} R_{2}=P P h A c e$

9: $E^{1} R_{2}=$ AsEtAce, $E^{2} R_{2}=P P h_{2}$

Figure 6. General NMR numbering scheme.

Caution! Arsenic halides are highly toxic powerful vesicants, which cause severe irritation and blistering if allowed to come in contact with skin. Suitable precautions, including the use of neoprene or rubber gloves, should be taken when handling these.

\subsection{Synthetic Methods}

4.2.1. $\mathrm{iPr}_{2} \mathrm{PAcenapPBr}_{2}$ (3)

To a cooled $\left(-78{ }^{\circ} \mathrm{C}\right)$ rapidly stirring solution of $2(2.60 \mathrm{~g}, 7.4 \mathrm{mmol})$ in diethyl ether $(60 \mathrm{~mL}), n$-butyllithium $(3.0 \mathrm{~mL}, 2.5 \mathrm{M}$ in hexane, $7.5 \mathrm{mmol}$ ) was added dropwise over $1 \mathrm{~h}$ and the mixture was left to stir for $2 \mathrm{~h}$ at the same temperature. The resulting suspension of $i \mathrm{Pr}_{2} \mathrm{PAcenapLi}$ was added via cannula (in small batches) over $1 \mathrm{~h}$ to a rapidly stirring solution of phosphorus tribromide $(9.90 \mathrm{~g}, 3.5 \mathrm{~mL}, 36.7 \mathrm{mmol})$ in diethyl ether $(30 \mathrm{~mL})$, cooled to $-78^{\circ} \mathrm{C}$. The reaction mixture was left to stir and warm to ambient temperature overnight. The orange suspension was filtered and the solid collected was washed with THF $(30 \mathrm{~mL})$ followed by diethyl ether $(30 \mathrm{~mL})$ to remove excess $\mathrm{PBr}_{3}$ and partially also $\mathrm{LiBr}$. After drying in vacuo, 3 (contaminated with $\mathrm{LiBr}$ ) was obtained as a yellow powder $(2.20 \mathrm{~g}, \sim 65 \%)$. Note that it is important when filtering the compound not to let the solid settle and compact as this will prevent removal of all $\mathrm{PBr}_{3}$. Crystals of 3 suitable for X-ray diffraction were grown from thf. Small scale recrystallisation from chloroform afforded analytically pure material. M. p. $168-172{ }^{\circ} \mathrm{C}$. Elemental Analysis Calcd. (\%) for $\mathrm{C}_{18} \mathrm{H}_{22} \mathrm{P}_{2} \mathrm{Br}_{2}$ : C 46.99, H 4.82; Found: C 47.07, H 4.87. ${ }^{1} \mathrm{H}$ NMR: $\delta_{\mathrm{H}}\left(400.1 \mathrm{MHz}, \mathrm{CDCl}_{3}\right)$ $8.82\left(1 \mathrm{H}, \mathrm{dd}(\sim \mathrm{t}),{ }^{3} J_{\mathrm{HH}}=6.8,{ }^{3} J_{\mathrm{HP}}=1.2 \mathrm{~Hz}, \mathrm{H}-8\right), 8.17\left(1 \mathrm{H}, \mathrm{dd},{ }^{3} J_{\mathrm{HH}}=7.2,{ }^{3} J_{\mathrm{HP}}=5.1 \mathrm{~Hz}\right.$, $\mathrm{H}-2), 7.73\left(1 \mathrm{H}, \mathrm{dd},{ }^{3} J_{\mathrm{HH}}=6.8,{ }^{4} J_{\mathrm{HP}}=2.4 \mathrm{~Hz}, \mathrm{H}-7\right), 7.62\left(1 \mathrm{H}, \mathrm{dd},{ }^{3} J_{\mathrm{HH}}=7.2,{ }^{4} J_{\mathrm{HP}}=2.8 \mathrm{~Hz}\right.$, $\mathrm{H}-3), 4.29-4.14\left(2 \mathrm{H}, \mathrm{m}(\sim\right.$ septet $\left.),{ }^{3} J_{\mathrm{HH}}=7.0 \mathrm{~Hz}, \mathrm{CH}\left(\mathrm{CH}_{3}\right)_{2}\right), 3.58(4 \mathrm{H}, \mathrm{br} \mathrm{s}, \mathrm{H}-11$ and $\mathrm{H}-12)$, $1.57\left(6 \mathrm{H},{ }^{2} J_{\mathrm{HP}}=19.2,{ }^{3} J_{\mathrm{HH}}=7.0 \mathrm{~Hz}, 2 \times \mathrm{CH}_{3}\right), 1.50\left(6 \mathrm{H}, \mathrm{dd},{ }^{2} J_{\mathrm{HP}}=19.5,{ }^{3} J_{\mathrm{HH}}=7.0 \mathrm{~Hz}\right.$, $\left.\left.2 \times \mathrm{CH}_{3}\right) .{ }^{13} \mathrm{C}^{1}{ }^{1} \mathrm{H}\right\}$ NMR: $\delta_{\mathrm{C}}\left(100.6 \mathrm{MHz}, \mathrm{CDCl}_{3}\right) 154.4(\mathrm{~s}, \mathrm{qC}-6), 151.8(\mathrm{~s}, \mathrm{qC}-4), 140.3(\mathrm{dd}$, $\left.{ }^{2} J_{\mathrm{CP}}=20.5,{ }^{2} J_{\mathrm{CP}}=3.4 \mathrm{~Hz}, \mathrm{qC}-10\right), 139.0\left(\mathrm{dd},{ }^{3} J_{\mathrm{CP}}=11.0,{ }^{3} J_{\mathrm{CP}}=1.5 \mathrm{~Hz}, \mathrm{qC}-5\right), 137.5(\mathrm{br} \mathrm{s}$, $\mathrm{C}-8), 134.8\left(\mathrm{dd},{ }^{2} J_{\mathrm{CP}}=31.5,{ }^{3} J_{\mathrm{CP}}=8.5 \mathrm{~Hz}, \mathrm{C}-2\right), 129.8\left(\mathrm{dd},{ }^{1} J_{\mathrm{CP}}=46.4,{ }^{2} J_{\mathrm{CP}}=4.7 \mathrm{~Hz}, \mathrm{qC}-1\right)$, $122.6(\mathrm{~s}, \mathrm{C}-3), 122.5(\mathrm{~s}, \mathrm{C}-7), 112.8\left(\mathrm{dd},{ }^{1} J_{\mathrm{CP}}=55.7,{ }^{2} J_{\mathrm{CP}}=8.0 \mathrm{~Hz}, \mathrm{qC}-9\right), 31.6(\mathrm{~s}, \mathrm{C}-11$ or C-12), $31.2\left(\mathrm{~s}, \mathrm{C}-11\right.$ or C-12), $27.5\left(\mathrm{dd},{ }^{1} J_{\mathrm{CP}}=28.5,{ }^{2} J_{\mathrm{CP}}=4.5 \mathrm{~Hz}, \underline{\mathrm{CH}}\left(\mathrm{CH}_{3}\right)_{2}\right), 18.8\left(\mathrm{br} \mathrm{s}, 2 \times \mathrm{CH}_{3}\right)$, $18.3\left(\mathrm{br} \mathrm{s}, 2 \times \mathrm{CH}_{3}\right) .{ }^{31} \mathbf{P}\left\{{ }^{1} \mathrm{H}\right\}$ NMR: $\delta_{\mathrm{P}}\left(162.0 \mathrm{MHz}, \mathrm{CDCl}_{3}\right) 65.3\left(\mathrm{~d}, \mathrm{P}_{\mathrm{PBr} 2}\right), 32.9\left(\mathrm{~d}, \mathrm{P}_{\mathrm{PiPr} 2}\right)$, ${ }^{1} J_{\mathrm{PP}}=353.7 \mathrm{~Hz} . \mathbf{I R}\left(\mathrm{KBr}\right.$ disc, cm $\left.{ }^{-1}\right) v=2963 \mathrm{vs}, 2934 \mathrm{vs}, 2862 \mathrm{~s}, 1457 \mathrm{~s}, 1443 \mathrm{~s}, 839 \mathrm{~m}, 640 \mathrm{~s}$. HRMS (APCI+): $\mathrm{m} / z$ (\%); Calcd. for $\mathrm{C}_{18} \mathrm{H}_{22} \mathrm{P}_{2} \mathrm{Br}(\mathrm{M}-\mathrm{Br}): 379.0375$, found 379.0376 (100). 


\subsection{2. $\mathrm{iPr}_{2} \mathrm{PAcenapAsBr}_{2}(4)$}

Compound 4 was prepared using the same procedure as per compound 3 except using the following: 2 (2.00 g, $5.7 \mathrm{mmol})$ in diethyl ether $(40 \mathrm{~mL}), n$-butyllithium $(2.3 \mathrm{~mL}, 2.5 \mathrm{M}$ in hexanes, $5.7 \mathrm{mmol}$ ) and arsenic tribromide $(1.80 \mathrm{~g}, 5.7 \mathrm{mmol})$ in diethyl ether $(50 \mathrm{~mL})$. Addition time of $\mathrm{Pr}_{2}$ PAcenapLi to $\mathrm{AsBr}_{3}$ was $3 \mathrm{~h}$. 4 was isolated as a yellow powder $(2.17 \mathrm{~g}$, $\sim 75 \%$ ). M. p. $159-161{ }^{\circ} \mathrm{C}$. Crystals suitable for $\mathrm{X}$-ray diffraction work were grown from benzene at room temperature. Contamination with residual $\mathrm{LiBr}$ prevented satisfactory microanalysis and accurate determination of the yield. ${ }^{1} \mathrm{H}$ NMR: $\delta_{\mathrm{H}}\left(500.1 \mathrm{MHz}, \mathrm{C}_{6} \mathrm{D}_{6}\right)$ $7.92\left(1 \mathrm{H}, \mathrm{d},{ }^{3} J_{\mathrm{HH}}=7.1 \mathrm{~Hz}, \mathrm{H}-8\right), 7.37\left(1 \mathrm{H}, \mathrm{dd},{ }^{3} J_{\mathrm{HP}}=8.6,{ }^{3} J_{\mathrm{HH}}=7.2 \mathrm{~Hz}, \mathrm{H}-2\right), 7.01(1 \mathrm{H}, \mathrm{dt}$, $\left.{ }^{3} J_{\mathrm{HH}}=7.2,{ }^{4} J_{\mathrm{HH}}=1.5 \mathrm{~Hz}, \mathrm{H}-7\right), 6.99\left(1 \mathrm{H}, \mathrm{dt},{ }^{3} J_{\mathrm{HH}}=7.2,{ }^{4} J_{\mathrm{HH}}=1.4 \mathrm{~Hz}, \mathrm{H}-3\right), 3.61(2 \mathrm{H}$, septet, $\left.{ }^{3} J_{\mathrm{HH}}=7.2 \mathrm{~Hz}, \underline{\mathrm{CH}}\left(\mathrm{CH}_{3}\right)_{2}\right), 2.89-2.73(4 \mathrm{H}, \mathrm{m}, \mathrm{H}-11$ and $\mathrm{H}-12), 1.36\left(6 \mathrm{H}, \mathrm{dd},{ }^{3} J_{\mathrm{HP}}=18.9\right.$, $\left.{ }^{3} J_{\mathrm{HH}}=7.2 \mathrm{~Hz}, 2 \times \mathrm{CH}_{3}\right), 1.14\left(6 \mathrm{H}, \mathrm{dd},{ }^{3} J_{\mathrm{HH}}=16.6,{ }^{3} J_{\mathrm{HH}}=7.3 \mathrm{~Hz}, 2 \times \mathrm{CH}_{3}\right) .{ }^{13} \mathrm{C}\left\{{ }^{1} \mathrm{H}\right\} \mathbf{N M R}:$ $\delta_{\mathrm{C}}\left(125.8 \mathrm{MHz}, \mathrm{C}_{6} \mathrm{D}_{6}\right) 153.2(\mathrm{~s}, \mathrm{qC}-4), 146.5(\mathrm{~s}, \mathrm{qC}-9), 145.8(\mathrm{~s}, \mathrm{qC}-5), 140.7\left(\mathrm{~d},{ }^{1} J_{\mathrm{CP}}=22.3 \mathrm{~Hz}\right.$, qC-1), $134.1(\mathrm{~s}, \mathrm{C}-2), 131.2\left(\mathrm{~d},{ }^{3} J_{\mathrm{CP}}=7.5 \mathrm{~Hz}, \mathrm{C}-8\right), 122.2(\mathrm{~s}, \mathrm{C}-7), 119.5\left(\mathrm{~d},{ }^{3} J_{\mathrm{CP}}=9.5 \mathrm{~Hz}, \mathrm{C}-3\right)$, $30.8\left(\mathrm{~s}, \mathrm{C}-11\right.$ or C-12), $30.2\left(\mathrm{~s}, \mathrm{C}-11\right.$ or C-12), $27.6\left(\mathrm{~d},{ }^{1} J_{\mathrm{CP}}=26.3 \mathrm{~Hz}, \underline{\mathrm{CH}}\left(\mathrm{CH}_{3}\right)_{2}\right), 20.0(\mathrm{~s}$, $\left.2 \times \mathrm{CH}_{3}\right), 17.7\left(\mathrm{~d},{ }^{2} J_{\mathrm{CP}}=5.7 \mathrm{~Hz}, 2 \times \mathrm{CH}_{3}\right) .{ }^{31} \mathrm{P}\left\{{ }^{1} \mathrm{H}\right\}$ NMR: $\delta_{\mathrm{P}}\left(202.5 \mathrm{MHz}, \mathrm{C}_{6} \mathrm{D}_{6}\right) 56.6(\mathrm{~s})$ MS (EI): $\mathrm{m} / z$ (\%) 422.97 (20) [M-Br], 344.04 (95) [M-2Br], 300.99 (90) [iPrPAcenapAs], 257.95 (95) [AcenapPAs], 234.74 (100) [ $\left.\mathrm{AsBr}_{2}\right]$.

\subsection{3. $\left[\mathrm{iPr}_{2} \mathrm{PAcenapAsBr}\right]^{+} \mathrm{Br}^{-} \cdot \mathrm{AsBr}_{3}$ (5) and $\left[\left(\mathrm{iPr}_{2} \mathrm{PAcenap}\right)_{2} \mathrm{As}_{2}\left[\mathrm{As}_{6} \mathrm{Br}_{8}\right](6)\right.$}

To a cooled $\left(-78^{\circ} \mathrm{C}\right)$ rapidly stirring solution of $2(2.00 \mathrm{~g}, 5.7 \mathrm{mmol})$ in diethyl ether (40 mL), $n$-butyllithium ( $2.3 \mathrm{~mL}, 2.5 \mathrm{M}$ in hexane, $5.7 \mathrm{mmol}$ ) was added dropwise over $1 \mathrm{~h}$ and the mixture was left to stir for $2 \mathrm{~h}$ at the same temperature. The resulting suspension of $i \mathrm{Pr}_{2} \mathrm{PAcenapLi}$ was added via cannula (in small batches) over $1 \mathrm{~h}$ to a rapidly stirring solution of arsenic tribromide $(3.60 \mathrm{~g}, 11.5 \mathrm{mmol})$ in diethyl ether $(80 \mathrm{~mL})$, cooled to $-78^{\circ} \mathrm{C}$. The reaction mixture was left to stir and warm to ambient temperature overnight. The suspension was filtered and the solid collected was washed with diethyl ether (30 mL). After drying in vacuo, 5 (contaminated with $\mathrm{LiBr}$ ) was obtained as a pale-yellow powder ( $3.84 \mathrm{~g}$, ca. $81 \%$ ). Crystals of 5 suitable for X-ray diffraction work were grown from THF at room temperature. Contamination with $\mathrm{LiBr}$ prevented satisfactory microanalysis and accurate determination of the yield. Solution NMR spectra of $\mathbf{5}$ are identical to those of 4 .

Few crystals of $\mathbf{6}$ suitable for diffraction work were obtained from recrystallisation of the crude product 5 from hot acetonitrile. No further characterisation was possible due to small amount available.

\subsection{4. (BrAcenap) $)_{2} \operatorname{AsEt}(7)$}

A solution of $n$-butyllithium ( $12.8 \mathrm{~mL}$ of $2.5 \mathrm{M}$ solution in hexanes, $32 \mathrm{mmol}$ ) was added dropwise to a rapidly stirred suspension of 5,6-dibromoacenaphthene $\mathbf{1}$ (10.0 g, $32 \mathrm{mmol})$ in THF $(120 \mathrm{~mL})$ at $-78^{\circ} \mathrm{C}$. The mixture was maintained for $2 \mathrm{~h}$ at this temperature. To this, a solution of ethyldiiodoarsine $(1.95 \mathrm{~mL}, 16 \mathrm{mmol})$ in THF $(20 \mathrm{~mL})$ was added dropwise over one hour at $-78{ }^{\circ} \mathrm{C}$. The resulting suspension was left to warm to room temperature overnight. The volatiles were removed in vacuo. Dichloromethane $(50 \mathrm{~mL})$ was added, and the resulting suspension was filtered. The product was obtained as a white powder after removal of the volatiles from the filtrate in vacuo. Recrystallisation of the crude material from dichloromethane gave 7 as colourless needle crystals ( $5.37 \mathrm{~g}$, $82 \%$ ), some of these were suitable for X-ray diffraction work. M. p. $199-200{ }^{\circ} \mathrm{C}$. Elemental analysis: Calcd. (\%) for $\mathrm{C}_{26} \mathrm{H}_{21} \mathrm{AsBr}_{2}$ : $\mathrm{C} 54.96, \mathrm{H} 3.72$; found: $\mathrm{C} 54.86, \mathrm{H}$ 3.65. ${ }^{1} \mathrm{H}$ NMR: $\delta_{\mathrm{H}}\left(400.1 \mathrm{MHz}, \mathrm{CD}_{2} \mathrm{Cl}_{2}\right) 7.60\left(2 \mathrm{H}, \mathrm{d},{ }^{3} J_{\mathrm{HH}}=7.4 \mathrm{~Hz}, \mathrm{H}-8\right), 7.48\left(2 \mathrm{H}, \mathrm{d},{ }^{3} J_{\mathrm{HH}}=7.2 \mathrm{~Hz}, \mathrm{H}-2\right)$, $7.08\left(2 \mathrm{H}, \mathrm{d},{ }^{3} J_{\mathrm{HH}}=7.2 \mathrm{~Hz}, \mathrm{H}-3\right), 7.00\left(2 \mathrm{H}, \mathrm{d},{ }^{3} \mathrm{~J}_{\mathrm{HH}}=7.4 \mathrm{~Hz}, \mathrm{H}-7\right), 3.29-3.19(8 \mathrm{H}, \mathrm{m}, \mathrm{H}-11$ and H-12), $\left.2.04\left(2 \mathrm{H}, \mathrm{q},{ }^{3} \mathrm{~J}_{\mathrm{HH}}=7.7 \mathrm{~Hz}, \mathrm{As}-\mathrm{CH}_{2}\right), 1.19\left(3 \mathrm{H}, \mathrm{t},{ }^{3} J_{\mathrm{HH}}=7.6 \mathrm{~Hz}, \mathrm{CH}_{3}\right) .{ }^{13} \mathrm{C}^{1}{ }^{1} \mathbf{H}\right\}$ NMR: $\delta_{\mathrm{C}}\left(100.6 \mathrm{MHz}, \mathrm{CD}_{2} \mathrm{Cl}_{2}\right) 146.2(\mathrm{~s}, \mathrm{qC}), 145.7(\mathrm{~s}, \mathrm{qC}), 140.7(\mathrm{~s}, \mathrm{qC}), 135.6(\mathrm{~s}, \mathrm{qC}), 134.6$ (s, C-2), 133.0 (s, C-8), 132.3 (s, qC), 119.4 (s, C-3), 119.2 (s, C-7), 115.5 (s, qC), 29.1 (s, C-11 or C-12), 28.8 (s, C-11 or C-12), $23.0\left(\mathrm{~s}, \mathrm{As}-\mathrm{CH}_{2}\right), 10.4\left(\mathrm{~s}, \mathrm{CH}_{3}\right)$. IR Data $\left(\mathrm{KBr}\right.$ disc, $\left.\mathrm{cm}^{-1}\right)$ : $v=3025 \mathrm{w}\left(v_{\mathrm{ArH}}\right), 2920 \mathrm{~s}, 2863 \mathrm{w}\left(v_{\mathrm{CH}}\right), 1603 \mathrm{~s}, 1411 \mathrm{~s}, 1320 \mathrm{vs}, 1251 \mathrm{~m}, 1200 \mathrm{~m}, 1100 \mathrm{~m}$, 
$1044 \mathrm{~m}, 836 \mathrm{vs}, 738 \mathrm{~m}, 602 \mathrm{~m}, 543 \mathrm{~m}$. Raman (glass capillary, $\left.\mathrm{cm}^{-1}\right) \mathrm{v}=3063 \mathrm{~m}\left(\mathrm{v}_{\mathrm{ArH}}\right)$, 2952 m, 2932 s, $\left(v_{\mathrm{CH}}\right), 1608$ m, 1561 vs, 1442 vs, 1412 s, 1345 m, 1320 vs, 815 m, 702 s, 577 vs, 557 s, 290 vs. MS (ES+) m/z (\%) 591 (100) [M + Na]. HRMS: $m / z$ Calcd. for $\mathrm{C}_{26} \mathrm{H}_{21} \mathrm{Br}_{2} \mathrm{AsNa}$ $(\mathrm{M}+\mathrm{Na}):$ 590.9103, found 590.9094 .

\subsubsection{Cyclo-PhP(Acenap $)_{2}$ AsEt (8)}

$N, N, N^{\prime}, N^{\prime}$-tetramethylethylene-1,2-diamine (TMEDA, $0.51 \mathrm{~mL}, 3.4 \mathrm{mmol}$ ) was added to a suspension of $7(0.75 \mathrm{~g}, 1.32 \mathrm{mmol})$ in THF $(35 \mathrm{~mL})$ and the mixture was cooled to $-78{ }^{\circ} \mathrm{C}$. A solution of $n$-butyllithium $(1.26 \mathrm{~mL}, 2.5 \mathrm{M}$ in hexanes, $3.2 \mathrm{mmol})$ was added dropwise with stirring over $1 \mathrm{~h}$. The solution was maintained at $-78{ }^{\circ} \mathrm{C}$ for $30 \mathrm{~min}$ before being warmed up and maintained at 0 to $10^{\circ} \mathrm{C}$ for an hour. The solution was re-cooled to $-78{ }^{\circ} \mathrm{C}$ and a solution of $\mathrm{PhPCl}_{2}(0.18 \mathrm{~mL}, 1.32 \mathrm{mmol})$ in THF $(5 \mathrm{~mL})$ was added dropwise. The mixture was left to warm up to room temperature overnight with stirring. The volatiles were removed in vacuo and replaced with dichloromethane $(30 \mathrm{~mL})$ and the resulting suspension was filtered. Removal of the volatiles in vacuo once again gave $\mathbf{8}$ as a yellow solid $(0.48 \mathrm{~g}$, ca. $70 \%)$. Crystals suitable for X-ray diffraction were grown from dichloromethane. Elemental analysis: The recrystallised material did not give satisfactory elemental analysis, presumably because of the contamination of the material with inorganic salts; the data fitted 8.1.45LiBr: calcd. (\%) for $\mathrm{C}_{32} \mathrm{H}_{26} \mathrm{AsP} \cdot(\mathrm{LiBr})_{1.45}$ : C 59.83, $\mathrm{H}$ 4.08; found: C 60.03, H 3.99. ${ }^{1} \mathrm{H}$ NMR: $\delta_{\mathrm{H}}\left(300.1 \mathrm{MHz}, \mathrm{CD}_{2} \mathrm{Cl}_{2}\right) 7.96\left(2 \mathrm{H}, \mathrm{dd},{ }^{3} J_{\mathrm{HH}}=7.2,{ }^{3} J_{\mathrm{HP}}=4.5 \mathrm{~Hz}\right.$, $\mathrm{H}-8), 7.81-7.74(2 \mathrm{H}, \mathrm{m}, o-\mathrm{Ph}), 7.59\left(2 \mathrm{H}, \mathrm{d},{ }^{3} J_{\mathrm{HH}}=7.3 \mathrm{~Hz}, \mathrm{H}-2\right), 7.46-7.38(2 \mathrm{H}, \mathrm{m}, m-\mathrm{Ph})$, 7.38-7.31 $(1 \mathrm{H}, \mathrm{m}, p-\mathrm{Ph}), 7.20\left(4 \mathrm{H},{ }^{3} \mathrm{~J}_{\mathrm{HH}}=7.2 \mathrm{~Hz}, \mathrm{H}-3\right.$ and $\left.\mathrm{H}-7\right), 3.39-3.16(8 \mathrm{H}, \mathrm{m}, \mathrm{H}-11$ and $\mathrm{H}-12), 2.28\left(2 \mathrm{H}, \mathrm{q},{ }^{3} \mathrm{~J}_{\mathrm{HH}}=7.7 \mathrm{~Hz}, \mathrm{As}-\mathrm{CH}_{2}\right), 1.54\left(3 \mathrm{H}, \mathrm{t},{ }^{3} \mathrm{~J}_{\mathrm{HH}}=7.7 \mathrm{~Hz}, \mathrm{CH}_{3}\right) .{ }^{13} \mathrm{C}\left\{{ }^{1} \mathrm{H}_{\}}\right.$ NMR was not acquired due to low solubility of $8 .{ }^{31} \mathbf{P}\left\{{ }^{1} \mathbf{H}\right\} \mathbf{N M R}$ : $\delta_{\mathrm{P}}\left(121.5 \mathrm{MHz}, \mathrm{CD}_{2} \mathrm{Cl}_{2}\right)$ $\delta_{\mathrm{P}}=-26.5(\mathrm{~s})$. IR $\left(\mathrm{KBr}\right.$ disc, $\left.\mathrm{cm}^{-1}\right): v=3071 \mathrm{w}\left(v_{\mathrm{Ar}-\mathrm{H}}\right), 2962 \mathrm{~s}\left(v_{\mathrm{C}-\mathrm{H}}\right), 1325 \mathrm{~s}, 1260 \mathrm{vs}, 1095 \mathrm{vs}$, br, 1022 vs, 802 vs, 735 s, $701 \mathrm{~m}$. Raman (glass capillary, $\left.\mathrm{cm}^{-1}\right)$ v $=3068 \mathrm{~m}\left(v_{\mathrm{Ar}-\mathrm{H}}\right), 2919 \mathrm{~m}$ $\left(v_{\mathrm{C}-\mathrm{H}}\right), 1603 \mathrm{~m}, 1583 \mathrm{vs}, 1565 \mathrm{~s}, 1330 \mathrm{vs}, 997 \mathrm{~s}, 537$ s, 253 m. MS (CI+): $m / z(\%) 517.1$ (58) $[\mathrm{M}+\mathrm{H}], 487.1$ (100) [M-Et]. HRMS (CI+): $m / z$ Calcd. for $\mathrm{C}_{32} \mathrm{H}_{27} \mathrm{AsP}(\mathrm{M}+\mathrm{H}): 517.1066$, found 517.1059.

\subsection{6. $\left(\mathrm{Ph}_{2} \mathrm{PAcenap}\right)_{2} \mathrm{AsEt}(\mathbf{9})$}

TMEDA $(0.51 \mathrm{~mL}, 3.4 \mathrm{mmol})$ was added to a suspension of $7(750 \mathrm{mg}, 1.32 \mathrm{mmol})$ in THF $(35 \mathrm{~mL})$ and the mixture was cooled to $-78^{\circ} \mathrm{C}$. A solution of $n$-butyllithium $(1.26 \mathrm{~mL}$, $2.5 \mathrm{M}$ in hexanes, $3.2 \mathrm{mmol}$ ) was added dropwise with stirring over $1 \mathrm{~h}$. The solution was maintained at $-78{ }^{\circ} \mathrm{C}$ for $30 \mathrm{~min}$ before being warmed up and maintained at 0 to $10{ }^{\circ} \mathrm{C}$ for an hour. The solution was re-cooled to $-78^{\circ} \mathrm{C}$ and a solution of chlorodiphenylphosphine $(0.49 \mathrm{~mL}, 2.64 \mathrm{mmol})$ in THF $(5 \mathrm{~mL})$ was added dropwise over $45 \mathrm{~min}$. The solution was left to warm to room temperature overnight with stirring. The volatiles were removed in vacuo and replaced with dichloromethane $(30 \mathrm{~mL})$, and the resulting mixture was filtered. Removal of the volatiles in vacuo once again gave 9 as a pale yellow solid $(0.52 \mathrm{~g}$, $\sim 52 \%$ ). Crystals suitable for X-ray diffraction were obtained in the form of monoxide 9a from dichloromethane. ${ }^{1} \mathbf{H}$ NMR: $\delta_{\mathrm{H}}\left(500.1 \mathrm{MHz}, \mathrm{CD}_{2} \mathrm{Cl}_{2}\right) 7.51\left(2 \mathrm{H}, \mathrm{d},{ }^{3} \mathrm{~J}_{\mathrm{HH}}=7.0 \mathrm{~Hz}\right.$, H-2), 7.26-7.13 (12H, br m, H-7 and H-8 and $m-\mathrm{Ph}), 7.10-7.03$ (2H, br m, H-3), 7.02-6.95 $(4 \mathrm{H}$, br m, p-Ph), $6.76(8 \mathrm{H}, \mathrm{br} \mathrm{s}, o-\mathrm{Ph}), 3.37-3.24(8 \mathrm{H}, \mathrm{m}, \mathrm{H}-11$ and $\mathrm{H}-12), 2.19(2 \mathrm{H}, \mathrm{q}$, $\left.{ }^{3} J_{\mathrm{HH}}=7.6 \mathrm{~Hz}, \mathrm{As}-\mathrm{CH}_{2}\right), 1.32\left(3 \mathrm{H}, \mathrm{t},{ }^{3} \mathrm{~J}_{\mathrm{HH}}=7.6 \mathrm{~Hz}, \mathrm{CH}_{3}\right) .{ }^{13} \mathrm{C}\left\{{ }^{1} \mathbf{H}\right\} \mathbf{N M R}: \delta_{\mathrm{C}} \mathrm{NMR}$ was not acquired due to low solubility of $\mathbf{9}^{31} \mathbf{P}\left\{{ }^{1} \mathbf{H}\right\} \mathbf{N M R}: \delta_{\mathrm{P}}\left(121.5 \mathrm{MHz}, \mathrm{CD}_{2} \mathrm{Cl}_{2}\right) \delta_{\mathrm{P}}=-19.9$ (s). IR $\left(\mathrm{KBr}\right.$ disc, $\left.\mathrm{cm}^{-1}\right): v=3044 \mathrm{~m}\left(v_{\mathrm{Ar}-\mathrm{H}}\right), 2962 \mathrm{vs},\left(v_{\mathrm{C}-\mathrm{H}}\right), 1601 \mathrm{~s}, 1477 \mathrm{~s}, 1261 \mathrm{vs}, 1020 \mathrm{vs}$, br, 800 vs, 693 vs. Raman (glass capillary, $\left.\mathrm{cm}^{-1}\right)$ v = $3047 \mathrm{vs},\left(v_{\mathrm{Ar}-\mathrm{H}}\right), 2930 \mathrm{~s}\left(\mathrm{v}_{\mathrm{C}-\mathrm{H}}\right), 1604 \mathrm{~s}$, 1583 s, 1325 vs, 998 vs, 536 vs. MS (CI+): m/z (\%) 779.1 (8) [M + H], 749.1 (16) [M-Et], 412.1 (32) [Ph $\mathrm{Ph}_{2}$ PAcenapAs]. HRMS (CI+) m/z Calcd. for $\mathrm{C}_{50} \mathrm{H}_{42} \mathrm{P}_{2} \mathrm{As}(\mathrm{M}+\mathrm{H}): 779.1978$, found 779.1977 . 


\section{Conclusions}

Utilising peri-substitution, novel dative complexes bearing pnictogen dibromide acceptor groups have been isolated and fully characterised. While their stability resembles that of their chlorine analogues, compounds 3 and $\mathbf{4}$ are thermally stable up to well above $100{ }^{\circ} \mathrm{C}$ and can be stored as solids under an inert atmosphere indefinitely, which makes them interesting for further synthetic use. Using excess $\mathrm{AsBr}_{3}$ gave species 5, in which a bromine atom of molecule 4 is ionically separated through interactions with co-crystallised molecules of $\mathrm{AsBr}_{3}$. The structures of 3-5 illustrate that in phosphine-pnictine complexes the local polarity (packing) effects within the crystal lattice result in rather different $\mathrm{Pn}-\mathrm{X}$ bond distances due to the fine balance of the polar covalent and ionic bonding around the (formally) negatively charged pnictoranido motifs. This is further corroborated by computational evaluation of the close As...As interaction observed in 4, which is found to consist mostly of dispersion forces.

Isolation of compound $\mathbf{6}$ indicates disproportionationative redox instability of $\mathbf{5}$ at elevated temperatures, resulting in an unusual heterocubane dianion $\left[\mathrm{As}_{6} \mathrm{Br}_{8}\right]^{2-}$, containing As(I) motifs.

Reaction of BrAcenapLi with EtAsI ${ }_{2}$ afforded no singly substituted species, only geminally disubstituted species 7 . This compound has been shown to be a useful synthon, with the As-C bonds being tolerant to the strong base $n \mathrm{BuLi}$. Thus, treatment of $\mathbf{7}$ with $n \mathrm{BuLi}$ proceeds through lithium-halogen exchange; subsequent reactions with chlorophosphine electrophiles afforded the new species, cyclic 8 and acyclic 9 .

Supplementary Materials: The following are available online at, File S1: Experimental data, including general considerations, preparation of arsenic tribromide, $\mathrm{X}$-ray diffraction and computational details [28,35,37-57]. Accession Codes CCDC 2116902-2116908 contain the supplementary crystallographic data for this paper. These data can be obtained free of charge via www.ccdc.cam.ac.uk/ data_request/cif, accessed on 28 October 2021, or by emailing data_request@ccdc.cam.ac.uk, or by contacting The Cambridge Crystallographic Data Centre, 12 Union Road, Cambridge CB2 1EZ, UK; Fax: +44-1223-336033. The research data underpinning this publication can be accessed at DOI https:/ / doi.org/10.17630/7bae9495-1422-4bae-aa2b-d160ce8c1d3f.

Author Contributions: P.K., B.A.C. and D.M.U.K.S. conceived and designed the project; B.A.C., D.M.U.K.S. and B.A.S. performed the experiments; A.M.Z.S. and K.S.A.A. did the crystallography; P.K., B.A.C. and J.D.W. contributed to writing the manuscript, M.B. did the computations. All authors have read and agreed to the published version of the manuscript.

Funding: This research was funded by the Engineering and Physical Sciences Research Council (EPSRC, Grant EP/J500549/1 and EP/M506631/1), COST action CM1302 SIPs and CM0802, and the EaStCHEM School of Chemistry.

Data Availability Statement: The research data underpinning this publication can be accessed at DOI https:/ / doi.org/10.17630/7bae9495-1422-4bae-aa2b-d160ce8c1d3f.

Acknowledgments: The authors thank the Engineering and Physical Sciences Research Council (EPSRC, Grant EP/J500549/1 and EP/M506631/1), COST action CM1302 SIPs and CM0802, and the EaStCHEM School of Chemistry for support. M.B. thanks H. Früchtl for technical assistance with the computations.

Conflicts of Interest: The authors declare no conflict of interest.

Sample Availability: Samples of all compounds are not available from the authors.

\section{References}

1. Peruzzini, M.; Gonsalvi, L. Phosphorus Compounds; Springer: Berlin/Heidelberg, Germany, 2011; Volume 37.

2. Greenwood, N.N.; Earnshaw, A. Chemistry of the Elements, 2nd ed.; Elsevier: Oxford, UK, 1997.

3. Crabtree, R.H. The Organometallic Chemistry of the Transition Metals, 5th ed.; John Wiley and Sons Inc.: Hoboken NJ, USA, 2009.

4. Holmes, R.R.; Bertaut, E.F. The Reduction of Phosphorus and Antimony Chlorides by Trimethylarsine and Trimethylstibine. J. Am. Chem. Soc. 1958, 80, 2983-2985. [CrossRef] 
5. Holmes, R.R.; Bertaut, E.F. The Reactions of Phosphorus and Antimony Chlorides with Trimethylamine, Triethylamine and Trimethylphosphine1. J. Am. Chem. Soc. 1958, 80, 2980-2983. [CrossRef]

6. Spangenberg, S.F.; Sisler, H.H. Reactions of some tri-n-alkylphosphines with some chlorophosphines. Inorg. Chem. 1969, 8, 1006-1010. [CrossRef]

7. Muller, G.; Matheus, H.J.; Winkler, M. Donor-Acceptor Complexes between Simple Phosphines. First Structural Data for an Almost Forgotten Class of Compounds. Z. Nat. B J. Chem. Sci. 2001, 56, 1155-1162. [CrossRef]

8. Wawrzyniak, P.; Fuller, A.L.; Slawin, A.M.Z.; Kilian, P. Intramolecular Phosphine-Phosphine Donor-Acceptor Complexes. Inorg. Chem. 2009, 48, 2500-2506. [CrossRef] [PubMed]

9. Summers, J.C.; Sisler, H.H. Reactions of some trialkyls of phosphorus, arsenic, or antimony with some organohalophosphines, -arsines, or -stibines. Inorg. Chem. 1970, 9, 862-869. [CrossRef]

10. Chitnis, S.S.; Burford, N.; McDonald, R.; Ferguson, M.J. Prototypical Phosphine Complexes of Antimony(III). Inorg. Chem. 2014, 53, 5359-5372. [CrossRef] [PubMed]

11. Hill, N.J.; Levason, W.; Reid, G. Arsenic(iii) halide complexes with phosphine and arsine co-ligands: Synthesis, spectroscopic and structural properties. J. Chem. Soc. Dalton Trans. 2002, 1188-1192. [CrossRef]

12. Burt, J.; Levason, W.; Reid, G. Coordination chemistry of the main group elements with phosphine, arsine and stibine ligands. Coord. Chem. Rev. 2014, 260, 65-115. [CrossRef]

13. Robertson, A.P.M.; Gray, P.A.; Burford, N. Interpnictogen Cations: Exploring New Vistas in Coordination Chemistry. Angew. Chem. Int. Ed. 2014, 53, 6050-6069. [CrossRef] [PubMed]

14. Chitnis, S.S.; Burford, N. Phosphine complexes of lone pair bearing Lewis acceptors. Dalton Trans. 2015, 44, 17-29. [CrossRef]

15. Chalmers, B.A.; Bühl, M.; Athukorala Arachchige, K.S.; Slawin, A.M.Z.; Kilian, P. Geometrically Enforced Donor-Facilitated Dehydrocoupling Leading to an Isolable Arsanylidine-Phosphorane. J. Am. Chem. Soc. 2014, 136, 6247-6250. [CrossRef]

16. Chalmers, B.A.; Bühl, M.; Athukorala Arachchige, K.S.; Slawin, A.M.Z.; Kilian, P. Structural, Spectroscopic and Computational Examination of the Dative Interaction in Constrained Phosphine-Stibines and Phosphine-Stiboranes. Chem. Eur. J. 2015, 21, 7520-7531. [CrossRef] [PubMed]

17. Hupf, E.; Lork, E.; Mebs, S.; Chęcińska, L.; Beckmann, J. Probing Donor-Acceptor Interactions in peri-Substituted Diphenylphosphinoacenaphthyl-Element Dichlorides of Group 13 and 15 Elements. Organometallics 2014, 33, 7247-7259. [CrossRef]

18. Carmalt, C.J.; Cowley, A.H.; Culp, R.D.; Jones, R.A.; Kamepalli, S.; Norman, N.C. Synthesis and Structures of Intramolecularly Base-Coordinated Group 15 Aryl Halides. Inorg. Chem. 1997, 36, 2770-2776. [CrossRef] [PubMed]

19. Taylor, L.J.; Bühl, M.; Wawrzyniak, P.; Chalmers, B.A.; Woollins, J.D.; Slawin, A.M.Z.; Fuller, A.L.; Kilian, P. Hydride Abstraction and Deprotonation-An Efficient Route to Low Coordinate Phosphorus and Arsenic Species. Eur. J. Inorg. Chem. 2016, 2016, 659-666. [CrossRef]

20. Ray, M.J.; Slawin, A.M.Z.; Buehl, M.; Kilian, P. peri-Substituted Phosphino-Phosphonium Salts: Synthesis and Reactivity. Organometallics 2013, 32, 3481-3492. [CrossRef]

21. Taylor, L.J.; Buhl, M.; Chalmers, B.A.; Ray, M.J.; Wawrzyniak, P.; Walton, J.C.; Cordes, D.B.; Slawin, A.M.Z.; Woollins, J.D.; Kilian, P. Dealkanative Main Group Couplings across the peri-Gap. J. Am. Chem. Soc. 2017, 139, 18545-18551. [CrossRef]

22. Nejman, P.S.; Curzon, T.E.; Bühl, M.; McKay, D.; Woollins, J.D.; Ashbrook, S.E.; Cordes, D.B.; Slawin, A.M.Z.; Kilian, P. PhosphorusBismuth Peri-Substituted Acenaphthenes: A Synthetic, Structural, and Computational Study. Inorg. Chem. 2020, 59, $5616-5625$. [CrossRef]

23. Kilian, P.; Slawin, A.M.Z.; Woollins, J.D. Preparation and structures of 1,2-dihydro-1,2-diphosphaacenaphthylenes and rigid backbone stabilized triphosphenium cation. Dalton Trans. 2006, 2175-2183. [CrossRef] [PubMed]

24. Chalmers, B.A.; Meigh, C.B.E.; Nejman, P.S.; Bühl, M.; Lébl, T.; Woollins, J.D.; Slawin, A.M.Z.; Kilian, P. Geminally Substituted Tris(acenaphthyl) and Bis(acenaphthyl) Arsines, Stibines, and Bismuthine: A Structural and Nuclear Magnetic Resonance Investigation. Inorg. Chem. 2016, 55, 7117-7125. [CrossRef] [PubMed]

25. Furan, S.; Hupf, E.; Boidol, J.; Brunig, J.; Lork, E.; Mebs, S.; Beckmann, J. Transition metal complexes of antimony centered ligands based upon acenaphthyl scaffolds. Coordination non-innocent or not? Dalton Trans. 2019, 48, 4504-4513. [CrossRef]

26. Gabes, W.; Olie, K. Refinement of the crystal structure of phosphorus pentabromide, PBr5. Acta Crystallogr. Sect. B Struct. Crystallogr. Cryst. Chem. 1970, 26, 443-444. [CrossRef]

27. Hubert, S.; Wolfgang, B.; Brigitte, H.; Gerhard, M. Arene Adducts with Weak Interactions: Hexaethylbenzene-bis(tribromoarsane). Angew. Chem. Int. Ed. Engl. 1987, 26, 234-236. [CrossRef]

28. The WBI is a measure for the covalent character of a bond and adopts values close to 1 and 2 for true single and double bonds, respectively: Wiberg, K.B. Application of the pople-santry-segal CNDO method to the cyclopropylcarbinyl and cyclobutyl cation and to bicyclobutane. Tetrahedron 1968, 24, 1083-1096. [CrossRef]

29. Müller, U.; Sinning, H. Octabromocyclohexaarsenate, [As6Br8] $]^{2}$. Angew. Chem. Int. Ed. Engl. 1989, 28, 185-186. [CrossRef]

30. Ellis, B.D.; Macdonald, C.L.B. Stabilized Arsenic(I) Iodide: A Ready Source of Arsenic Iodide Fragments and a Useful Reagent for the Generation of Clusters. Inorg. Chem. 2004, 43, 5981-5986. [CrossRef] [PubMed]

31. Batsanov, S.S. Van der Waals Radii of Elements. Inorg. Mater. 2001, 37, 871-885. [CrossRef]

32. Tanaka, N.; Kasai, T. Reactions of 5,6-Dilithioacenaphthene- $N, N, N^{\prime}, N^{\prime}$-Tetramethyl-1,2-ethanediamine Complex with $\alpha$-Diketones. I.cis-Directing 1:1 Cyclic Additions with Acyclic and Cyclic $\alpha$-Diketones and Related Compounds. Bull. Chem. Soc. Jpn. 1981, 54, 3020-3025. [CrossRef] 
33. Armarego, W.L.F.; Chai, C.L.L. Purification of Laboratory Chemicals, 6th ed.; Elsevier: Burlington, VT, USA, 2009.

34. Neudorff, W.D.; Lentz, D.; Anibarro, M.; Schlüter, A.D. The Carbon Skeleton of the Belt Region of Fullerene C84 (D2). Chem. Eur. J. 2003, 9, 2745-2757. [CrossRef]

35. Arnaiz, F.J.; Miranda, M.J.; Rheingold, A.L. Arsenic (III) Bromide. Inorg. Synth. 2002, 33, 203. [CrossRef]

36. Matuska, V.; Slawin, A.M.Z.; Woollins, J.D. Five-Membered Arsenic-Sulfur-Nitrogen Heterocycles, RAs(S2N2) (R = Me, Et, iPr, tBu, Ph, Mes). Inorg. Chem. 2010, 49, 3064-3069. [CrossRef] [PubMed]

37. Chalmers, B.A.; Somisara, D.M.U.K.; Surgenor, B.A.; Athukorala Arachchige, K.S.; Woollins, J.D.; Buehl, M.; Slawin, A.M.Z.; Kilian, P. Synthetic and Structural Study of peri-Substituted Phosphine-Arsines (Dataset); University of St Andrews Research Portal: St Andrews, UK, 2021. [CrossRef]

38. CrystalClear 2.0; Rigaku Americas: The Woodlands, TX, USA; Rigaku Corporation: Tokyo, Japan, 2007.

39. CrystalClear Software User's Guide; Molecular Structure Corportation, 2017.

40. Sheldrick, G. Crystal structure refinement with SHELXL. Acta Crystallogr. Sect. C 2015, 71, 3-8. [CrossRef] [PubMed]

41. Sheldrick, G. SHELXT-Integrated space-group and crystal-structure determination. Acta Crystallogr. Sect. A 2015, 71, 3-8. [CrossRef] [PubMed]

42. CrystalStructure 4.3.0; Rigaku Americas: The Woodlands, TX, USA; Rigaku Corporation: Tokyo, Japan, 2018.

43. Bruno, I.J.; Cole, J.C.; Edgington, P.R.; Kessler, M.; Macrae, C.F.; McCabe, P.; Pearson, J.; Taylor, R. New software for searching the Cambridge Structural Database and visualizing crystal structures. Acta Crystallogr. Sect. B 2002, 58, 389-397. [CrossRef] [PubMed]

44. Thomas, I.R.; Bruno, I.J.; Cole, J.C.; Macrae, C.F.; Pidcock, E.; Wood, P.A. WebCSD: The online portal to the Cambridge Structural Database. J. Appl. Crystallogr. 2010, 43, 362-366. [CrossRef]

45. Dolomanov, O.V.; Bourhis, L.J.; Gildea, R.J.; Howard, J.A.K.; Puschmann, H. OLEX2: A complete structure solution, refinement and analysis program. J. Appl. Crystallogr. 2009, 42, 339-341. [CrossRef]

46. Macrae, C.F.; Bruno, I.J.; Chisholm, J.A.; Edgington, P.R.; McCabe, P.; Pidcock, E.; Rodriguez-Monge, L.; Taylor, R.; van de Streek, J.; Wood, P.A. Mercury CSD 2.0-New features for the visualization and investigation of crystal structures. J. Appl. Crystallogr. 2008, 41, 466-470. [CrossRef]

47. Becke, A.D. Density-functional thermochemistry. III. The role of exact exchange. J. Chem. Phys. 1993, 98, 5648-5652. [CrossRef]

48. Lee, C.; Yang, W.; Parr, R.G. Development of the Colle-Salvetti correlation-energy formula into a functional of the electron density. Phys. Rev. B 1988, 37, 785-789. [CrossRef]

49. Grimme, S.; Antony, J.; Ehrlich, S.; Krieg, H. A consistent and accurate ab initio parametrization of density functional dispersion correction (DFT-D) for the 94 elements H-Pu. J. Chem. Phys. 2010, 132, 154104. [CrossRef]

50. Grimme, S.; Ehrlich, S.; Goerigk, L. Effect of the damping function in dispersion corrected density functional theory. J. Comput. Chem. 2011, 32, 1456-1465. [CrossRef]

51. Risthaus, T.; Grimme, S. Benchmarking of London Dispersion-Accounting Density Functional Theory Methods on Very Large Molecular Complexes. J. Chem. Theory Comput. 2013, 9, 1580-1591. [CrossRef] [PubMed]

52. Becke, A.D.; Johnson, E.R. Exchange-hole dipole moment and the dispersion interaction. J. Chem. Phys. 2005, 122, 154104. [CrossRef]

53. Johnson, E.R.; Becke, A.D. A post-Hartree-Fock model of intermolecular interactions: Inclusion of higher-order corrections. J. Chem. Phys. 2006, 124, 174104. [CrossRef] [PubMed]

54. Binning, R.C.; Curtiss, L.A. Compact contracted basis sets for third-row atoms: Ga-Kr. J. Comput. Chem. 1990, 11, 1206-1216. [CrossRef]

55. Boys, S.F.; Bernardi, F. The calculation of small molecular interactions by the differences of separate total energies. Some procedures with reduced errors. Mol. Phys. 1970, 19, 553-566. [CrossRef]

56. Reed, A.E.; Curtiss, L.A.; Weinhold, F. Intermolecular interactions from a natural bond orbital, donor-acceptor viewpoint. Chem. Rev. 1988, 88, 899-926. [CrossRef]

57. Frisch, M.J.; Trucks, G.W.; Schlegel, H.B.; Scuseria, G.E.; Robb, M.A.; Cheeseman, J.R.; Scalmani, G.; Barone, V.; Mennucci, B.; Petersson, G.A. Gaussian 09; Gaussian, Inc.: Wallingford, CT, USA, 2009. 